\title{
Earnings news and small traders
}

\author{
An intraday analysis*
}

\author{
Charles M.C. Lee \\ University of Michigan, Ann Arbor, MI 48109-1234, USA
}

Received September 1991, final version received March 1992

\begin{abstract}
This study separates trading volume into buyer- and seller-initiated activities and examines the directional volume reaction in small and large trades to different types of earnings news. "Good" ("bad") news triggers brief, but intense, buying (selling) in the large trades. However, a persistent period of unusually high buying activity is observed in the small trades irrespective of the news. This anomalous proclivity of small traders to buy is robust across firm size, trading volume, and different earnings expectation models. Several explanations are discussed, although the behavior does not seem fully explained by existing theories.
\end{abstract}

\section{Introduction}

This study investigates the intraday behavior of directional volume surrounding the release of different types of earnings news. In prior studies of earnings news and trading volume, the volume metric is a nondircetional, and the appropriate interpretation of abnormal volume has been a subject of debate. ${ }^{1}$

*This paper is based on sections of my Ph.D. dissertation. I thank my committee members Dale Morse (chair), George Casella, Richard Highfield, and Richard Thaler for their guidance and support. Extremely helpful comments were provided by Bill Cready, Mustafa Gultekin, Mark Ready, Seymour Smidt, Ross Watts (the editor), and Greg Clinch (the referee). I also benefited from suggestions received in workshops at Berkeley, Carnegie Mellon, Chicago, Cornell, Duke, Harvard, McMaster, Michigan, Pennsylvania, Rochester, Stanford, Toronto, Waterloo, and Yale. An earlier version was presented at the 1991 Western Financial Association meetings. The financial support of the Deloitte Haskins \& Sells Foundation, the Institute of Chartered Accountants of Ontario, and the Social Sciences and Humanities Research Council of Canada is gratefully acknowledged. This research is conducted using the Cornell National Supercomputer Facility, a resource of the Cornell Theory Center, which receives major funding from the National Science Foundation and IBM Corporation.

${ }^{1}$ See Karpoff (1986) for a good summary of different theories of volume. Holthausen and Verrecchia (1990), Kim and Verrecchia (1991), and Grundy and McNichols (1989) offer formal analyses in an event study context. Empirical studies of volume and earnings news include Bamber (1986, 1987) and Morse (1981). 
A recent study by Lee and Ready (1991) notes that most trades take place when one side of the transaction (a buyer or seller) demands immediate execution. Thus, it is usually possible to classify each trade as either buyer- or sellerinitiated. In this paper, the Lee and Ready (1991) algorithm is used to decompose abnormal volume into buyer- and seller-initiated trades. This approach permits the buy/sell reaction of investors to be directly observed, so that directional inferences may be drawn from the volume reaction of different types of earnings news.

When volume is decomposed in this manner, new insights into investor behavior emerge. For example, the buy/sell imbalance immediately before 'good' and 'bad' news releases is a measure of the extent of pre-announcement information 'leakage'. Similarly, the duration and adjustment path of the buy/sell imbalance after an earnings announcement provide new insights into how quickly market participants (as opposed to prices) adapt to the new equilibrium price.

This study uses the directional volume metric to examine the differential effect of earnings news on the instigators of small (low dollar value) and large (high dollar value) trades. The results show that in the pre-announcement period there is little abnormal volume and little evidence of information 'leakage', in that the proportion of buys (sells) is not significantly higher just before good (bad) news. In the half hour of the announcement, both small and large trades experience an abrupt increase in volume, which is sustained for several days. The volume reaction in small trades is 'weaker' than the reaction in large trades, in the sense that the abnormal volume in small trades represents a lower proportion of total trading for that size class. Consistent with Cready's (1988) analysis at the daily level, I find the small trade reaction to be 'slower' and, in addition, show that this derives mainly from the greater concentration of large trades in the first hours after the Broad Tape announcement.

In the post-announcement period, I find large trades respond to good (bad) news by a period of intense buying (selling) of short duration. The speed of adjustment in the large trade buy/sell imbalance mirrors the speed of the intraday price adjustment, such that both are largely undetectable after the first hour of trading. Thus, buys and sells in large trades quickly settle around the new equilibrium price. In contrast, the small trades display a puzzling propensity toward buys during earnings announcement periods irrespective of the type of news release. This abnormally high buying activity is robust across different earnings expectation models, and is found even in a sample of 'neutral' news releases. The persistent buying in small trades is also observed for subsample portfolios formed on the basis of firm size and trading volume, although it is more evident in smaller and less frequently traded firms. Alignment of the events by time-of-day shows that the small trade abnormal buying begins the day before the earnings release and is most intense on the morning after the Broad Tape news has been released. This surprising proclivity of small trades to be 
buys around earnings announcements does not seem fully explained by existing theories.

One interpretation of these findings is that small individual investors and professional/institutional traders differ systematically in their reaction to earnings news. The evidence on individual and institutional trades suggest a link between trade size and trader type. Even though trades below $\$ 10,000$ represent nearly $50 \%$ of the transactions for NYSE firms, Chen and Lakonishok (1991) show that few institutional trades are below $\$ 10,000 .^{2}$ In contrast, the 1985 NYSE Shareownership Survey reports that the median transaction size for various subgroups of individual investors ranged between $\$ 2,300$ and $\$ 8,540$. Thus, if individual investors differ from their professional counterparts in terms of trading behavior, this difference should be reflected in the trade size proxy. Extant evidence, primarily from surveys, shows individual investors trade much less often, spend far less time on investment analysis and typically rely on a very different set of information sources from their professional counterparts. ${ }^{3}$ This study posits that small traders will respond differently from large traders to the same earnings signal. The evidence is consistent with this hypothesis. ${ }^{4}$

The paper is related to several recent studies in finance and accounting. In finance, the focus has been on the potential pricing effect of individual investors. For example, Ritter (1988) observed that the daily buy/sell ratio for Merrill Lynch cash account clients (a noninstitutional clientele) explains $40 \%$ of the year-to year variation in the 'January Effect' - the tendency of small firms to outperform the market in January. Lakonishok and Maberly (1990) report an association between the 'Weekend Effect' - negative returns on Mondays - and the buy/sell ratio in odd-lot trades. Lee, Shleifer, and Thaler (1991) show that fluctuations in the discount of closed-end mutual funds (held primarily by noninstitutional traders) track abnormal returns on small firms, and activities in other market segments dominated by individual investors (such as initial public offcrings and nct redemptions on open-end mutual funds). In each case, the

\footnotetext{
'Chen and Lakonishok (1991) has unique dataset of 1.2 million known institutional trades transacted between 1986 and 1988 . The median trade is $\$ 80,000$ and only $10 \%$ of these trades is below $\$ 10,000$. Unfortunately it is not known whether these trades arise from market or limit orders. If a significant percentage were limit orders, it is possible the reported trade size (which reflects the active side of the trade) is smaller than the size of the original order. Thus, the percentage of institutional trades below $\$ 10,000$ is likely to be at most $10 \%$

${ }^{3}$ Evidence on trading frequency can be derived from ownership and volume information provided by NYSE Shareownership Surveys as well as the Securities Industry Association Investor Activity reports. Evidence on decision styles and information sources is presented in Lease, Lewellen, and Schlarbaum (1974), Lewellen, Lease, and Schlarbaum (1977), Yunker and Krehbiel (1988), Shiller and Pound (1989), and the Stanford Research Institute (SRI) (1987) survey.

${ }^{4}$ The small and large trader interpretation motivates this study and seems reasonable, given the collaborating evidence on individual and institutional trades. However, other explanations for these results are possible and some are discussed in the concluding section. As a minimum, these results suggest some traders are behaving differently from others - a finding that should be of interest even apart from the individual/institutional interpretation.
} 
differential behavior of small individual investors is offered as a potential explanation for a long-standing pricing anomaly.

A maintained hypothesis in these studies is that the buy/sell activities of small individual investors do not always correspond to those of large institutional investors - 'small money' does not move in lockstep with the 'big money'. Surprisingly, this hypothesis has never been tested directly using trade size proxies. In this paper, the issue is addressed in the context of a specific information event - earnings news. Divergent buy/sell reactions in large and small trades to the same earnings signal is at least consistent with the institulional/individual dichotomy hypothesized in these studies.

Two recent studies in accounting also provide additional insights on the issue. Cready (1988) finds that the abnormal volume reaction to announcements of earnings is weaker and slower in small trades. Cready attributes these findings to a positive relation between investors' wealth and the value of earnings information. In contrast, Cready and Mynatt (1991) show no significant volume reaction to the mailing of annual reports except in the smallest trade size stratum. Taken together, the evidence suggests small trades respond to different information signals from large trades. This study extends Cready (1988) by contrasting the directional reaction of small and large trades in an intraday framework. The buy/sell decisions of small and large traders are linked explicitly to 'good' and 'bad' news earnings as defined by different earnings expectation models. The findings show directional differences in the small and large trades even to the same information signal.

The rest of the paper is organized as follows. The next section discusses relevant market microstructure research design issues. Section 3 deals with data description and sample selection, section 4 covers statistical tests, and section 5 reports results. Section 6 summarizes the key findings and potential explanations and offers suggestions for future work.

\section{Market microstructure and research design}

The rules and procedures that govern the way orders are executed on the exchange floor can have a significant effect on the inferences made using intraday data. Two market microstructure issues, in particular, have important implications for the design of this study: the behavior of passive side traders and the credibility of the small trade proxy for individual investor behavior. These two issues are discussed in this section.

\subsection{Passive side activities}

Trading in equity securities on the New York Stock Exchange (NYSE) and American Stock Exchange (AMEX) generally involves a continuous two-sided 
auction. ${ }^{5}$ The trading process for each security is carried out at a specified location on the exchange floor and presided over by a specialist.

When an order is placed with a broker, the instigator of the order specifies not only the number of shares to be bought or sold, but also the mode of execution. A market order is to be executed immediately at the best available price. A limit order is an order to buy or sell when a specified price is attained (limit orders which are immediately executable are, in this context, considered to be market orders). The specialist maintains a list of limit orders at various prices on each side of the current quote. These orders are executed as prices move to the level specified in the order. When an order is large, it is sometimes more advantageous for a trader to issue a 'standing' order. A standing order is an order to buy or sell certain number of shares at the best available price over a certain time period. The order is given to a floor broker who is able to exercise discretion over the exact timing of the trades needed to fill the order by waiting in the 'crowd' at the specialist's post and responding to incoming orders by bettering the current quote. In terms of immediacy of execution, the market order is executed immediately, the standing order is like a limit order with priority execution and the limit order is only exercised when price conditions dictate.

In this setting it is possible to identify a passive and an active side to each trade, with the active side defined as the side with the greater need for immediate execution. This is because after the opening trade, trading only takes place when a market order arrives. ${ }^{6}$ The market order (the active side) is met either by a standing order or a limit order, or the specialist trading on his or her account (the passive side). With few exceptions, both the size and direction of a trade reflect the market order, or the active side, of the transaction. For example, when a larger market order is filled by several smaller limit orders (and possibly in part by the specialist), the transaction is recorded as a single transaction at the size of the market order. ${ }^{7}$

Note that the trade size proxy captures only one dimension of the market the activities of the active side. The trade size proxy does not reflect any changes which might occur on the passive side as a result of an information release. However, the active side should be the dimension of primary interest when studying the effect of public disclosures (i.e., event studies). This is because the active side reflects the behavior of market participants who demand immediate

\footnotetext{
${ }^{5}$ The exceptions are the opening trade of each day (which is a single call auction) and certain block trades (which are prearranged away from the exchange floor).

${ }^{6}$ Occasionally, a market buy and a market sell order will arrive simultaneously and be matched with each other, but this situation is rare.

${ }^{7}$ The exception is when there is insufficient depth at a given price, in which case a separate trade is recorded at each price level needed to fill the order. This would result in the original order being recorded as more than one smaller trade. Even in such situations, the smaller trades reflect the depth at a given price, not the size of the limit or standing orders which make up the passive side.
} 
execution. When an investor receives information that causes a revision in her beliefs about the value of a security, and she believes this information will cause a general price movement in the same direction, the appropriate action is to issue a market order - not a limit or standing order. Only a market order ensures execution as the price moves in the direction expected. A limit or standing order to buy at the bid price, for example, will not be executed at all if the investor is correct and the price moves upwards.

\subsection{The small trade proxy}

Any proxy for individual investor behavior based on trade size is inherently noisy. Some individual investors are capable of trading in volumes that are indistinguishable from professional investors. Other institutional investors might choose to trade in smaller blocks for strategic reasons. The approach taken here is to minimize the possibility of institutional activity in the small trades by selecting a low value threshold. This enhances the interpretability of the small trade proxy at the cost of losing the larger transactions made by individual investors.

Since small traders are defined in terms of the value of their investment base, a dollar-based threshold for classifying trades is most logical. Unfortunately a simple dollar-based classification scheme is sensitive to price movements and runs into implementation problems due to the discrete trading of shares in round lots of $100 . .^{8.9}$ An alternative is to use a share-based proxy, such as in Cready (1988). Unfortunately a share-based proxy is difficult to interpret in a wealth context since securities can trade in a wide price range.

To circumvent these problems, the small trade proxy for each firm was computed as follows:

1. Obtain the closing price of the firm as of December 30, 1988.

2. Compare the closing price to $\$ 10,000$ and determine the largest number of round lot shares that is less than or equal to $\$ 10,000$. Trades transacted during the year for this firm at this number of shares or less will be deemed small trades.

\footnotetext{
${ }^{8}$ The transaction data used does not separately identify odd-lot trades (transactions of less than 100 shares). During the study period, the total value of odd-lot trades is $0.7 \%$ of the total value of all shares transacted (NYSE Fact Book, 1988 edition).

${ }^{9}$ The problem with a simple dollar-based proxy is that price movements will cause different round-lot trades to be classified as 'small' trades. For example, if a stock is trading at $\$ 20$, a $\$ 10,000$ cutoff would classify all trades of 100-500 shares as small trades. If the stock moves to $20_{8}^{1}$, suddenly only $100-400$ share trades will be classified as 'small'. Since small traders are not likely to immediately adjust the size of their trades due to such small price changes, we will observe an immediate drop in the small trade volume which is artificially induced.
} 
For example, if the year-end price of a share is $\$ 30$, then all trades for this firm involving 300 shares or less will be deemed small trades. Similarly, for a $\$ 40$ stock, all trades of 200 shares or less will be deemed small trades. During 1988, year-end prices were generally close to their high for the year so virtually all trades classified as small trades by this method should be below $\$ 10,000$. Descriptive statistics presented later bears this out.

The $\$ 10,000$ threshold was selected after examining the findings of the NYSE Public Transactions Study (PTS) and the NYSE Shareownership Survey. ${ }^{10}$ It ensures the small trades will have little institutional activity yet still contain enough observations ( $45 \%$ of all trades) to provide statistical power comparable to the large trade stratum. Ideally, the trades should be divided into several size categories. However, the frequency of trades in half-hour intervals is too low to permit finer partitions without a substantial decrease in statistical power. To ensure the main findings are not sensitive to this threshold value, all major findings were recomputed using $\$ 5,000$ and $\$ 20,000$ cutoffs (a disadvantage of the $\$ 5,000$ threshold is that any firm with a trading price higher than $\$ 50$ will have no small trades). The results were qualitatively identical.

Apart from the assumptions already discussed, there are two other sources of potential noise in the small trade proxy: batching of small trades in the opening trade of each day and the effect of program trading. The former is controlled for by excluding from the analysis the first trade of each day which is not preceded by a BBO-eligible quote. ${ }^{11}$ The increased volatility in the volume measures introduced by programmed trading activities has the potential to diminish the power of statistical tests. However, during 1988 most programmed trades relate to index arbitrage activities between the futures and equity markets. This activity is not firm-specific and is not correlated with earnings announcement dates, so program trades should not bias the results in this study.

\footnotetext{
${ }^{10}$ The PTS is an extensive survey of trades transacted on the NYSE. The last PTS was conducted during the fourth quarter of 1980 . That study shows that in the 900 shares or less size stratum, $70.5 \%$ $(29.5 \%)$ of the publicly traded volume is due to trades by individual (institutional) investors. In the 1,000 shares or more stratum, $23.7 \%(76.3 \%)$ of all trading volume is individual (institutional). While the average shares per trade in the fourth quarter of 1980 was 762 , orders initiated by institutional investors averaged 1,700 shares and orders initiated by individual investors averaged 374 shares (these are means, the medians should be lower). As an alternative frame of reference, the 1985 NYSE Shareownership Survey attempts to profile the individual investor. That report finds the median transaction size for various subgroups of individual investors (classified by age, experience, etc.) ranged between $\$ 2,300$ and $\$ 8,540$.

${ }^{11}$ Quotes which are eligible for inclusion in the National Association of Security Dealer's best bid or offer calculation are call BBO-eligible quotes. My discussion with NYSE specialists indicate opening trades which precede a BBO-eligible quote generally reflect a clearing of accumulated orders. On the other hand, a trade which takes place after an opening quote has been established is generally not a clearing trade.
} 


\section{Data description and sample selection}

The transaction data used for this study were obtained from the Institute for the Study of Security Markets (ISSM) based at Memphis State University. The ISSM data includes information on all firms whose primary exchange listing is the NYSE or the AMEX, although only NYSE firms were selected for this study. All trades and quotes originating from the NYSE, AMEX, NASDAQ, or one of the regional exchanges are included. Each trade or quote is time-stamped (nearest second) and carries a code identifying the originating exchange. For trades, the price and volume is provided, as is a condition code if special conditions apply. For quotes, the bid price, ask price, depth on both sides, and a condition code (where applicable) are provided.

The period of coverage of the tape used in this study is the twelve-month period January 4, 1988 to December 30, 1988 -- 253 trading days. During this period the exchanges opened for 6.5 hours a day $9: 30$ to 4:00 EST, except the Pacific Exchange which operated at a half hour later). All trades between 9:30 and 4:15, including trades on regional exchanges, were included in this study. The reason for extending the closing time for 15 minutes is to pick up the trades which are time-stamped slightly later than 4:00, due to market-at-close orders, etc. This procedure picked up all but 2,525 trades $(0.06 \%$ of the total transacted by the sample firms). A review of these trades showed they were either related to activity on the Pacific Exchange or were reported late. When volume by time intervals were computed, trades with transaction times between 4:00 and 4:15 were included in the last trading period of the day.

The sample firms included in this study were selected from the 1988 ISSM transaction tape. The initial population consisted of all NYSE-listed common stock issues with a CUSIP identifier that were listed for the full year. This resulted in 1,463 firms. To facilitate the analysis, a series of restrictions on shares outstanding, trading activity, and price were imposed on these firms.

Table 1 details these filters and the number of firms that were removed through the sequential application of each filter. 604 firms remained after these filters. Due to cost considerations, a random sample of 302 firms was selected from this remaining population. After removing all regulated firms (utilities) and firms in specialized industries (closed-end funds and investment trust funds), a total of 230 firms remained.

For each firm, the date and time of all announcements of dividend changes and quarterly earnings were identified by searching the Dow Jones News Service (DJNS) for the period January 1, 1988 to December 31, 1988. The earnings announcement selected for analysis is the first announcement after the period end that provided an actual earnings figure. Occasionally an announcement would be corrected at a later time. In such cases the earlier announcement time is used. In light of earlier findings of abnormal volume and price effects around 
Table 1

Selection of sample firms. ${ }^{\mathbf{a}}$

Total NYSE firms listed for the full year in 1988

1,463

- Change in shares outstanding $>10 \%$

- Extreme large block trades

- Trading halts

- Averaged less than 10 trades per day

- Year-end price $<\$ 5$ or $>\$ 100$

Total remaining firms

Firms in a $50 \%$ random sample

Less: Firms in specialized or regulated industries

Total sample firms

${ }^{a}$ The sample selection criteria in the order applied were:

Change in shares outstanding $>10 \%$ - Substantial changes in the total shares outstanding will affect the volume statistics as well as the small trade proxy, thus issues for which the total shares outstanding changed by more than $10 \%$ during the year are removed.

Extreme block trades - Firms that experienced a trade exceeding 3.276 million shares are removed since the effect of such a trade will likely distort trading patterns not only in the vicinity of the trade but also after its occurrence. The size of the cutoff reflects the ISSM tape definition of extreme trades. Trading halts - The trading on a security may be temporarily suspended for the dissemination of news or when a severe imbalance of buy/sell orders occurs. While not a common occurrence, these trading halts have a disproportionalely large effect on intraday trading patterns. King, Pownall, and Waymire (1991, forthcoming) show very few halts are related to earnings announcements.

Low volume - Issues that are very thinly traded present a problem when intraday inferences are made. Thus firms that averaged less than ten trades a day are removed from the sample.

Closing price $<\$ 5$ and $>\$ 100$ - Requiring the closing price to be higher than $\$ 5$ ensures that small trades will not exceed 2,000 shares even for the lowest priced stocks. Restricting the price to $\$ 100$ ensures the cost of the smallest round lot is less than $\$ 10,000$.

Industry exclusions Firms in certain industries either do not report earnings (closed-end mutual funds, real estate investment trusts) or report earnings that are subject to regulatory reviews (utilities). These are excluded.

announcements of changes in dividend policy [Patell and Wolfson (1984)], 117 such announcements were also identified and controlled for in the analysis.

The Value Line Investment Survey forecast of quarterly earnings per share (EPS) from the most recent issue immediately preceding the announcement date is used to proxy for market expectations about earnings. To ensure the EPS is calculated consistently, the actual reported EPS from the DJNS was also checked against the actual EPS reported in the Value Line issue immediately following the announcement. In case of differences, the Value Line figure is used.

In 1988, the Broad Tape operated from around 7:45 a.m. to around 6:45 p.m., so an announcement may occur before the market opens or after the market is closed. Given the focus of this study on the intraday dissemination process, only announcements made during trading hours are included, although the potential confounding effects of the other announcements are controlled for by excluding 
them from the nonannouncement control sample. ${ }^{12}$ When an earnings announcement is expected but not found in the DJNS, it is located in the Wall Street Journal Index. Since the exact times of such announcements are not known, they were excluded from the analysis. However, to control for their effect on trading activities, the three days centered on the Wall Street Journal announcement date were removed from the analysis. Similarly, when the announcement of a dividend change occurred within three days of an earnings announcement, days 0 to +2 relative to each announcement were removed from the analysis. After removing these confounding events, a total of 607 intraday earnings announcements remained. Of these announcements $63 \%$ occurred before $12: 30$ p.m., with the highest concentration $(12 \%$ of total) occurring in the half-hour interval 10:00-10:30 a.m. However, there is no pronounced clustering in any particular half-hour interval.

A total of 4,076,190 trades (approximately one sixth of total NYSE trades during 1988) were transacted by the sample firms. Using a $\$ 10,000$ value threshold, $1,833,363$ trades $(45.0 \%$ of total trades in the sample firms) were classified as small, $98.2 \%$ of all small trades are below $\$ 10,000$ in value and $95.2 \%(97.0 \%)$ are $500(900)$ shares or less.

\section{Statistical tests}

The basic measure of volume used throughout this study is:

$$
f_{i t}^{z}=\frac{\text { No. of firm } i \text { trades of size } z \text { during period } t}{\text { Total no. of firm } i \text { trades of size } z \text { during year }} \times 100
$$

where $z$ is a trade size indicator such that: $z=\mathrm{s}$ signifies small trades as determined by the $\$ 10,000$ firm-specific threshold, $z=1$ signifies large trades as determined by the $\$ 10,000$ threshold, and $z=\mathrm{a}$ signifies all trades.

A share-based volume metric was also used in sensitivity tests. Since the key findings of the study are not affected by the choice of the volume metric, only the results based on $f_{i i}^{z}$ are reported here.

A modified version of the Patell and Wolfson (1984) variance test is used to infer statistical significance. The actual procedures taken are as follows. First, over a control sample of nonannouncement periods (periods that exclude all dividend and earnings announcements), the multinominal frequency distribution of trading volume is computed for each firm, each size stratum, and each

\footnotetext{
${ }^{12}$ In light of the Patell and Wolfson (1982) finding that good news tends to be released during the day and bad news during hours when the market is closed, this procedures will likely remove more bad news announcements than good news announcements. However, separate examination of the remaining good news and bad news releases should mitigate against any selection bias.
} 
half-hour interval of the trading day. Since there are 13 half-hour intervals per day and 3 size strata, 39 separate frequency distributions are computed for each firm. For each distribution, the sample median value $\left(m_{i k}^{z}\right)$ and the top quartile value $\left(q_{i k}^{z}\right)$ are computed, together with the probability that a random draw from the distribution will exceed its sample median $\left(P M_{i t}^{z}\right)$ or its first quartile value $\left(P Q_{i t}^{z}\right)$. The subscript $k=1, \ldots, 13$ indicates the time period of the day, the subscripts $z$ and $i$ indicate the firm and size class. If volume measures were continuous, $P M_{i i}^{z}$ and $P Q_{i t}^{z}$ would be 0.5 and 0.25 , respectively. Unfortunately volume measures are discrete and over small time intervals these measures can be quite coarse, so that more than one observation may assume the sample median or first quartile value. To ensure these differences in the reference distributions are accounted for, separate $P M_{i t}^{z}$ and $P Q_{i t}^{z}$ values are determined for each reference distribution.

To aggregate across firms, a Normal approximation to a generalized form of the Binomial test is used. Under the null hypothesis of zero volume effect, the probability that an observed volume will exceed its nonevent median (first quartile) is $P M_{i t}^{z}\left(P Q_{i t}^{z}\right)$. Thus, the total expected number of observed values which exceed their corresponding medians (first quartiles) is simply the sum of the $P M_{i t}^{z}\left(P Q_{i t}^{z}\right)$ values. In large samples, the following statistics are distributed approximately Normal $(0,1)$ :

$$
\begin{gathered}
\text { YMed }{ }_{r}^{z}=\frac{\left(V M_{r}^{z}-0.5-\sum_{i, t} P M_{i t}^{z}\right)}{\sqrt{\sum_{i, t} P M_{i t}^{z}\left(1.0-P M_{i t}^{z}\right)}}, \\
Y Q n_{r}^{z}=\frac{\left(V Q_{r}^{z}-0.5-\sum_{i, t} P Q_{i t}^{z}\right)}{\sqrt{\sum_{i, t} P Q_{i t}^{z}\left(1.0-P Q_{i t}^{z}\right)}},
\end{gathered}
$$

where $V M_{r}^{z}\left(V Q_{r}^{z}\right)$ is the actual number of observations that exceeded its median (first quartile) value in size stratum $z$ and event period $r(r=-13$ to +38$)$. The subtraction of 0.5 from the numerator is a correction for continuity [see Snedecor and Cochran (1980, p. 119)].

To compute $V M_{r}^{z}\left(V Q_{r}^{z}\right)$, all announcements are aligned in event time. For each half-hour interval in the event window, the observed trading volume of each firm is compared to the median (first quartile) of the corresponding nonevent distribution. $V M_{r}^{z}\left(V Q_{r}^{z}\right)$ is the total number of announcements which exceed the median (first quartile) value. 
The test above measures the pervasiveness of the abnormal volume reaction in each time interval over the event window, but does not offer an estimate of the magnitude of the abnormal volume. This is provided by the following mean abnormal volume $(M A V)$ and cumulative mean abnormal volume (CMAV) measures:

$$
M A V_{r}^{z}=\frac{1}{n_{r}} \sum_{i=1}^{n_{r}}\left(f_{i t}^{z}-\overline{f_{i k}^{z}}\right), \quad C M A V_{r}^{z}=\sum_{j=-13}^{r} M A V_{j}^{z},
$$

where $\overline{f_{i k}^{z}}$ is the mean volume measure across all nonannouncement days for firm $i$, time period $k(k=1, \ldots, 13)$ and trade size $z ; n_{r}$ is the number of observations in event interval $r(r=-13, \ldots,+38)$.

\section{Results}

\subsection{Volume reaction}

Fig. 1 shows the mean abnormal volume $(M A V)$ for the large and small trade size groups. The shadings for each column indicates the significance levels for the $z$-statistics. ${ }^{13}$ The vertical height of each column indicates the magnitude of the $M A V$ in each time period. For reference, it is helpful to note that the average trading volume in each half hour, unconditional on an earnings event, is 0.0304 . The results show a much stronger reaction from the large trade stratum. In the large trades, the $M A V$ for the 0 and +1 intervals is over $100 \%$ of the normal volume of trade. In contrast, the $M A V$ in the same two intervals in the small trade stratum is roughly $50 \%$ of the normal volume of trade. Thus, a greater proportion of the total annual large trades are concentrated around earnings announcements. This is at least consistent with the survey evidence that small individual investors focus less on earnings news than institutional investors.

Even within the four-day event window, there is evidence that the intraday pattern of abnormal volume differs across the two size classes. Fig. 1 shows that large trades are more concentrated on the Broad Tape release time, while small trades tend to be more dispersed across the next three trading days. To provide a more direct comparison of the adjustment paths, the mean abnormal volume $(M A V)$ for each time interval is divided by the total cumulative mean abnormal volume ( $C M A V$ ) for the 52 event intervals. Fig. 2 plots the $C M A V$ adjustment paths for each size stratum and reports the time required to reach $10 \%, 25 \%$,

\footnotetext{
${ }^{13}$ In reading the figures, it is helpful to keep in mind that significance levels are based on the proportion of announcements that exceed the medians of their reference distributions. Thus, a statistically significant reaction is one that is broadly-based, not one in which the $M A V$ exceeds a critical value. It is therefore possible for some large $M A V$ to be insignificant and some small $M A V$ to be significant.
} 
$50 \%, 75 \%$, and $90 \%$ of the full $C M A V$ adjustment. This analysis provides a sense of how quickly the abnormal volume manifests itself in each size class over the event window. Some care needs to be taken in interpreting these results, since they are clearly sensitive to the size of the event window. However, fig. 2 suggests that the abnormal volume in large trades is more focused on the Broad Tape news release. When the same procedures were applied to portfolios formed on the basis of firm size (large and small) and trading frequency (high and low), the findings were similar.

\subsection{Directional reaction (order imbalance)}

As indicated earlier, this papcr cmploys a new algorithm that allows a different direction measure for the two size strata. A description of the algorithm, together with summary statistics on the number of trades classified by each step, is presented in the appendix. While the exact accuracy of this algorithm will be sample-specific, the empirical and analytical tests in Lee and Ready (1991) suggest a success rate of approximately $95 \%$. For a more detailed explanation of the algorithm, as well as tests of its performance, see Lee and Ready (1991).

News is classifiable as good or bad only in relation to prior investor expectations. In this study several empirical models of investor expectations for earnings are used. The first assumes the Value Line forecast is a reasonable proxy for investors' expectation of earnings. Announcements of earnings higher (lower) than the Value Line forecast are deemed good (bad) news. Announcements for which there is either no Value Line forecast, or where the forecast is equal to the actual earnings, are considered 'neutral news'. The second model classifies the announcements based on the price change around the event. Announcements accompanied by a price increase (decrease) in the first hour of trading after the release are deemed good (bad) news. ${ }^{14}$ To avoid noise introduced by the bid-ask spread, the mean of the bid and ask prices (the 'midspread') is used in computing the price change. The third model assumes investors' expectations of earnings follow a seasonal random walk, so that earnings higher (lower) than that reported in the corresponding quarter in the prior year is deemed good (bad) news.

Since the key results are similar using all three models, only the findings for the Value Line forecast are reported here. Table 2 summarizes the announcements that are classified as 'good', 'bad', and 'neutral' on the basis of the

\footnotetext{
${ }^{14}$ Announcement 'misclassifications' are less likely if the price change is computed over a longer time period. However, since the direction measure is related to price changes, such a classification scheme would render the results difficult to interpret. For example, when announcements are divided on the basis of the sign of the one-day return, strong directional imbalances in the direction of the price change are found for the full trading day after release. In effect, this result is predetermined.
} 

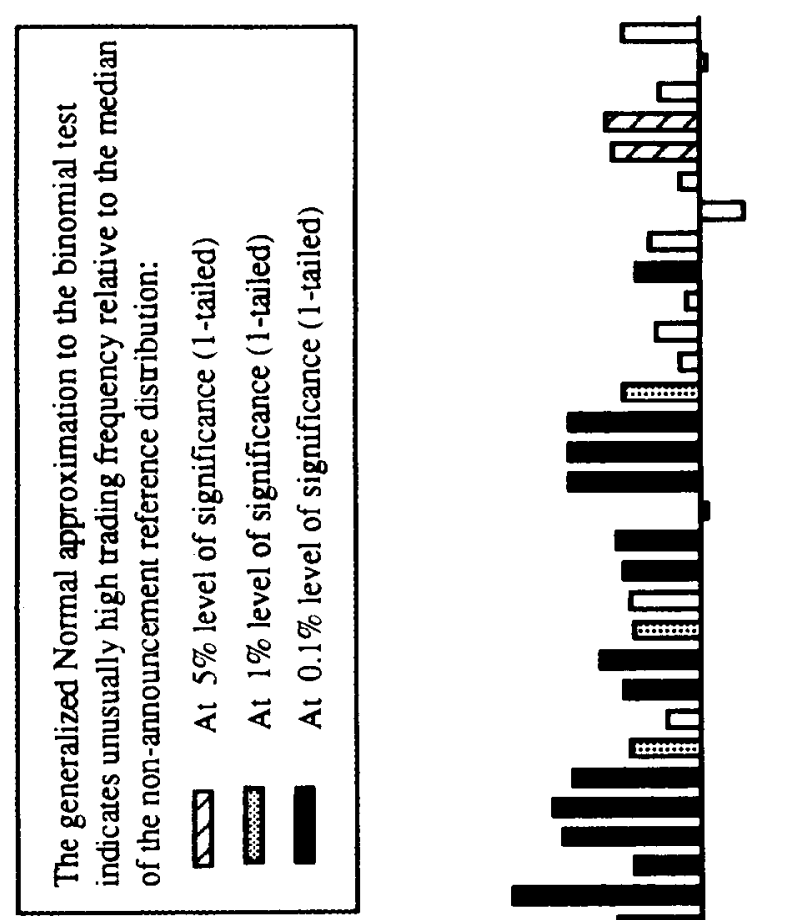


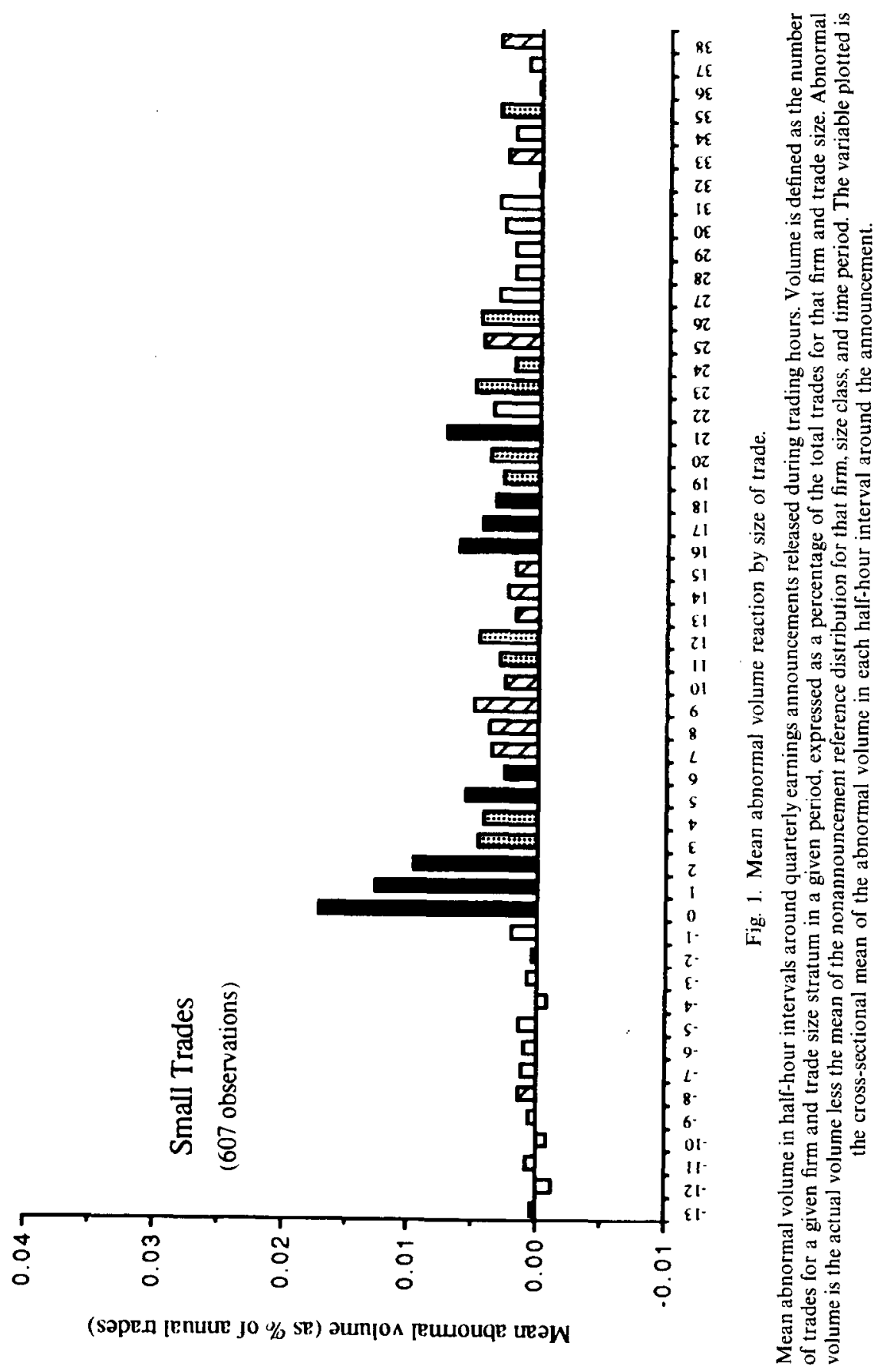




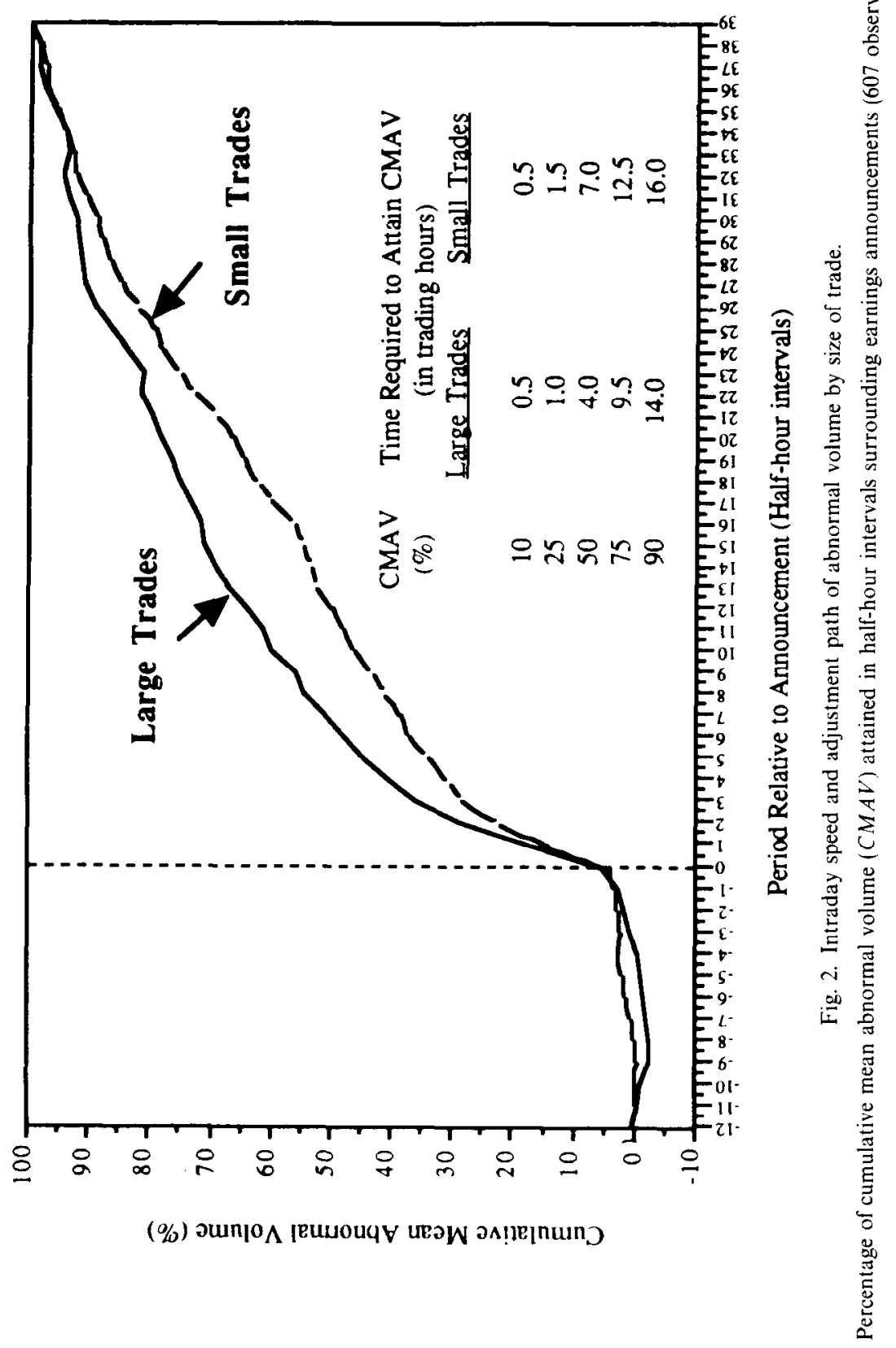


Table 2

Summary statistics for good news, bad news, or indeterminable announcements, classified on the basis of the sign of the Value Line forecast error.

\begin{tabular}{lcccc}
\hline & Full sample & Good news & Bad news & $\begin{array}{c}\text { Indeter- } \\
\text { minable }\end{array}$ \\
\hline Number of announcements & 607 & 261 & 240 & 106 \\
$\begin{array}{l}\text { Number of announcements by sign } \\
\text { of the price change in the first hour } \\
\text { of trading: }\end{array}$ & & & & \\
$\quad \begin{array}{l}\text { Positive price change } \\
\quad \text { Negative price change }\end{array}$ & 237 & 140 & 62 & 35 \\
$\quad \begin{array}{l}\text { No price change } \\
\begin{array}{c}\text { Average one-hour return } \\
\text { after announcement }\end{array}\end{array}$ & 197 & 64 & 100 & 33 \\
$\begin{array}{l}\text { Average one-day return } \\
\text { after announcement }\end{array}$ & $0.09 \%$ & $0.52 \%$ & $-0.25 \%$ & $-0.15 \%$ \\
\hline
\end{tabular}

Value Line forecast error. As indicated, the mean one-day returns are negative (positive) for bad (good) news under either classification.

The most direct way to compute an aggregate direction measure is to align the announcements in event time and sum the number of buys and sells for each time interval across all announcements. This 'pooling' approach, which is similar to the Patell and Wolfson (1984) test for price continuations, would be acceptable if the observations were independent. Unfortunately, at the transaction level, there is strong positive serial correlation in the occurrence of buys and sells. Thus, when a single firm-interval contains more than one trade, these observations are positively correlated even during nonevent periods. In the presence of positive correlation, the variance estimate in the above methods will underestimate the actual variance. This can result in inflated test statistics.

To circumvent the serial correlation problem, the trades for each firm in each half-hour interval are aggregated into a single direction measure:

$$
F D I R_{i t}^{z}=\frac{F B U Y_{i t}^{z}-F S E L L_{i t}^{z}}{T R D_{i}^{z}} \times 100
$$

where $F B U Y_{i l}^{z}\left(F S E L L_{i t}^{z}\right)$ is the number of buy (sell) orders for firm $i$, trade size $z$, and time interval $t$, and $T R D_{t}^{z}$ is the total number of trades of size $z$ for firm $i$ during the year. $F D I R_{i t}^{z}$ is a frequency-based measure of the direction of trading in period $t$ (a shares-based measure was also computed and results were similar). Higher values of $F D I R_{i t}^{z}$ correspond to a higher proportion of buys to sells. Deflating by the total trading activity for the firm allows for aggregation across firms and provides a sense of the 'weight' of the direction movement. In 


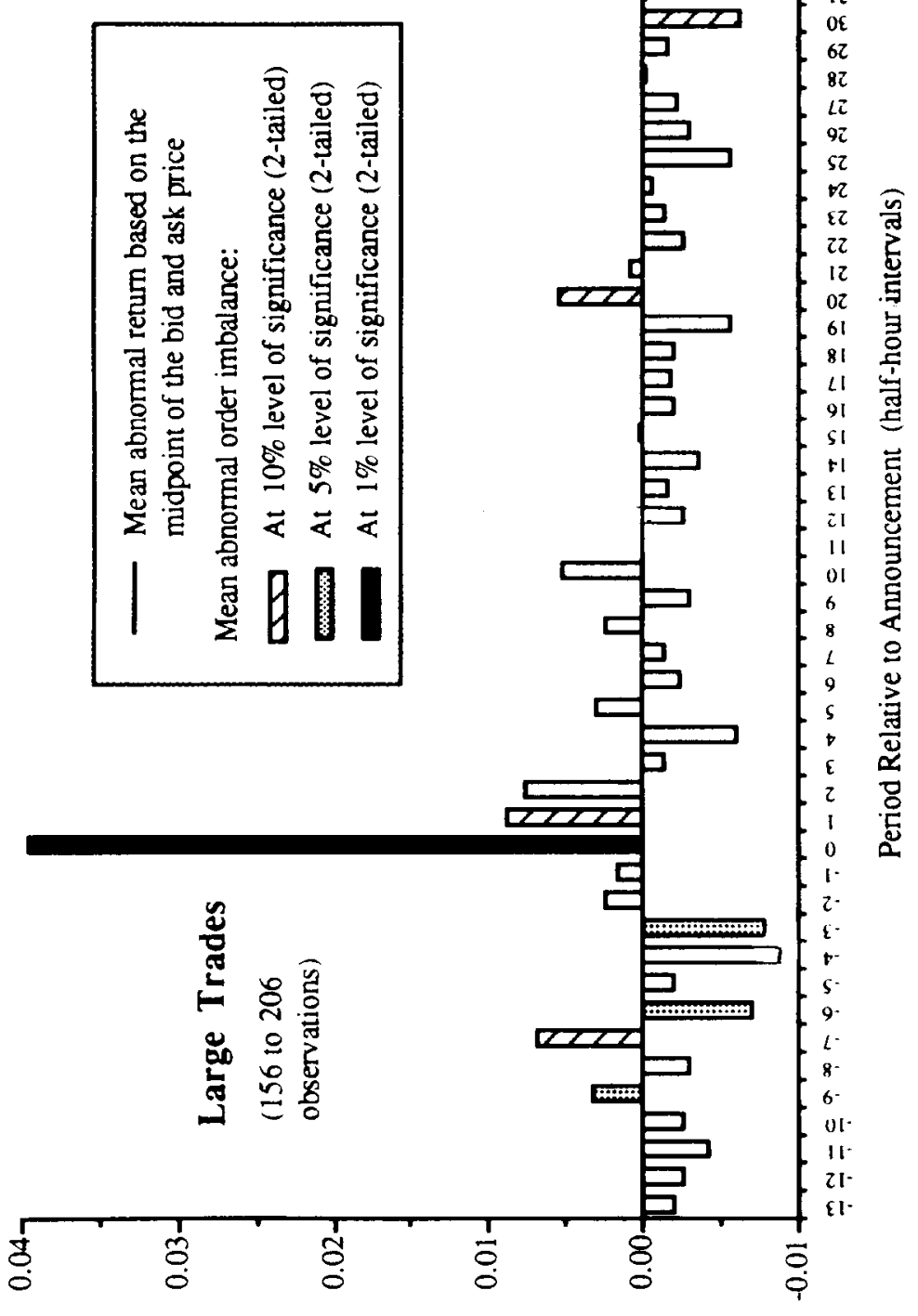

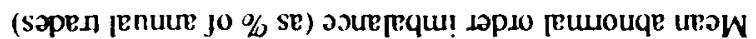



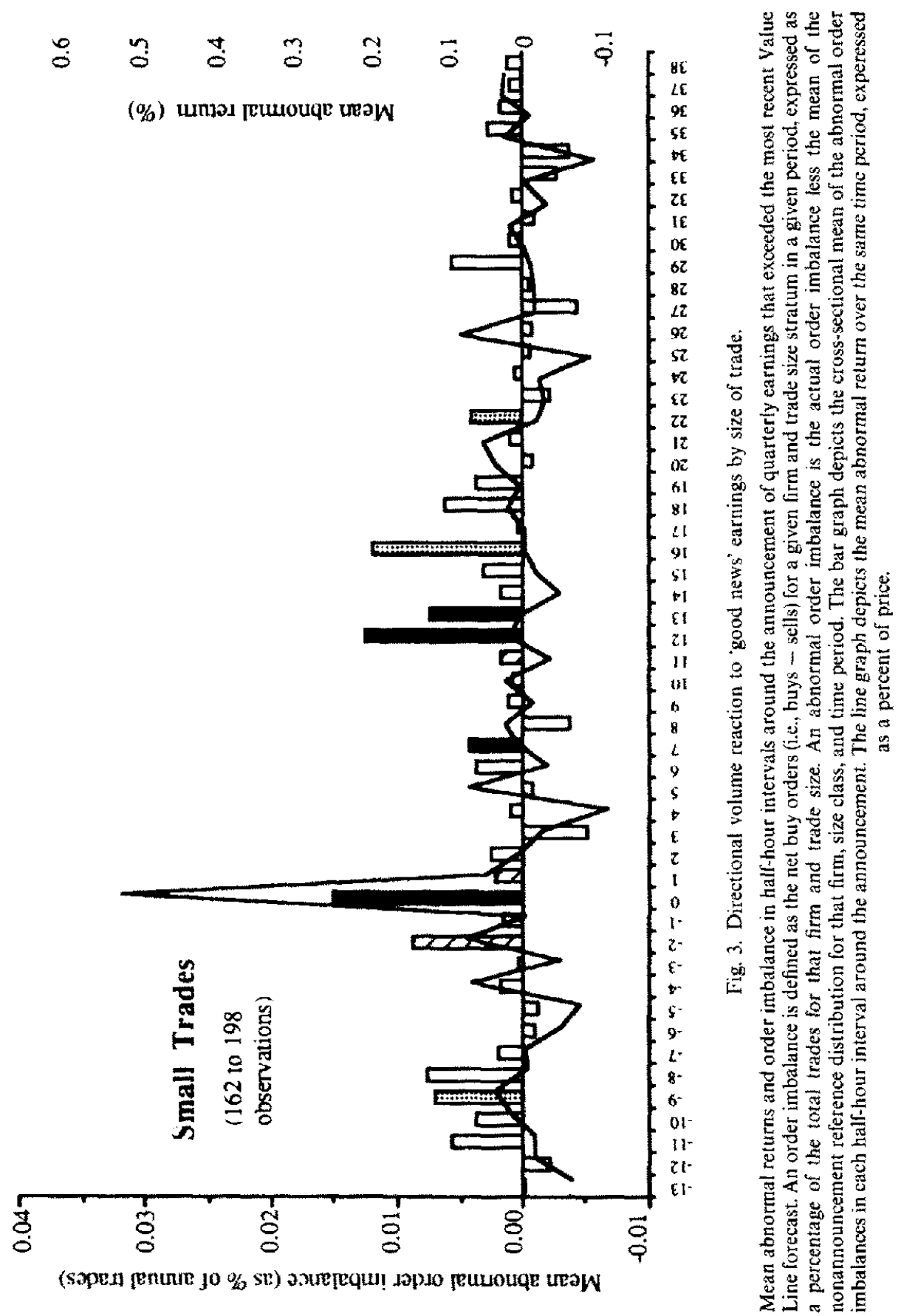
a procedure completely analogous to the generalized binomial test used earlier, the multinomial distribution for $F D I R_{i t}^{z}$ is computed over nonevent periods and the actual measure over the event period is compared to this distribution. ${ }^{15}$

To provide an estimate of the magnitude of the abnormal order imbalance in each time interval across the event window, the following mean abnormal directional imbalance measure $(M A D)$ is computed:

$$
M A D_{r}^{z}=\frac{1}{m_{r}^{z}} \sum_{i=1}^{m_{r}^{z}}\left(F D I R_{i t}^{z}-\overline{F D I R_{i k}^{z}}\right),
$$

where $\overline{F D I R_{i k}^{z}}$ is the mean direction measure across all nonannouncement days for firm $i$ and time period $k(k=1, \ldots, 13)$ and trade size $z, m_{r}^{z}$ is the number of announcements for which there was at least one size $z$ trade in event period $r(r=-13, \ldots,+38)$.

Fig. 3 presents the mean abnormal directional imbalance measure ( $\left.M A D_{r}\right)$ for large and small trades when the actual earnings exceed the Value Line forecast ('good' news). Also plotted in the lower graph is the price reaction, as measured by the mean abnormal return for each half-hour interval over the event window. As explained earlier, intraday returns are computed using the midpoint of the bid-ask price at the end of each half hour. The abnormal return is the actual return minus the mean of the reference distribution for that firm and time-of-day. The figure plotted is the equal-weighted mean abnormal return across all announcements.

As expected, the price reaction to earnings in excess of Value Line forecasts is positive. The mean abnormal return in the half hour containing the Broad Tape release of 'good news' is just over $0.5 \%$ and is statistically significant at the $1 \%$ level (two-tailed). Consistent with prior findings [e.g., Patell and Wolfson (1984)], this price reaction dissipates quickly and is significantly positive only for interval 0.

The direction imbalance in the large trade stratum is significantly positive in time interval 0 , suggesting abnormally high buying activities. However, like the price reaction, this response is extremely short-lived, lasting only 30 minutes. In the small trade stratum, there is also a strong positive reaction in interval 0 . Ilowever, unlike the large trade stratum, abnormally high buying imbalances are observed for at least the next 13 intervals. Since the price has already adjusted to the information shock, the protracted buying by small traders seems

\footnotetext{
${ }^{15}$ One important modification is that $F D I R_{\mathrm{f}}^{z}$ is defined only when there is trading of size $z$ in period $t$. In other words, zero trade intervals are not included in either the computation of the nonevent distribution or in the event period analysis. The problem with including zero trade intervals is that in periods of higher volume (such as immediately after an announcement), the probability of exceeding the nonevent distribution median increases even when there is no directional movement, simply as a result of fewer nontrading observations.
} 
to suggest that, on average, the small traders believe the new equilibrium price is too low. However, the evidence is also consistent with the small traders systematically lagging the market response. There is also some weak indication of directional imbalances in the preannouncement period which is positive for small trades but negative for large trades.

Fig. 4 reports the price reaction and directional imbalance when the news is 'bad' based on the Value Line forecast error. As expected, the price adjustment is negative and occurs largely in the first half hour. Once again, the order imbalance in large trades is strong in interval 0 , only this time it is negative, indicating abnormally high selling. The duration of the large trader reaction seems slightly longer for bad news, but is still essentially undetectable after 90 minutes. $^{16}$ Surprisingly, there is no reaction from the small trade stratum in the first five time intervals after the announcement. From interval 6 onwards, however, there appears to be a period of protracted buying in the small trades. Again, this is consistent with the interpretation that small traders deem the new equilibrium price to be too low. It is not consistent, however, with the explanation that small traders systematically lag the market response.

To ensure the surprising results in figs. 3 and 4 are not due to a misspecified statistical test, two calibration tests were performed. First, for each announcement that exceeded the most recent Value Line forecast, an observation was generated using the same firm and lime of day, but a random announcement date. A similar test was performed for a portfolio of 'bad news' announcements. The results, not reported, show no significant patterns in the imbalance measures in either random sample. In particular, it is not the case that the small trade stratum is prone to abnormal buying. It is also not the case that statistically significant observations occur more frequently in the small trade stratum.

To further characterize this propensity of small traders to buy around earnings releases, I examined a sample of announcements which either were not classifiable by Value Line or did not result in a price change in the first hour of trading. The price and directional response of large and small trades is documented for this 'neutral' news subsample in fig. 5.

There is no significant price reaction at the time of the news release, although the one-day return for this portfolio is slightly negative. Large trades also do not display any significant directional volume imbalance during the event period. However, in the small trades the now familiar pattern of buying emerges once again. There is some evidence that for this sample the unusual buying activity begins on day -1 .

\footnotetext{
${ }^{16}$ In time interval 1 , the mean abnormal buy measure is strongly negative, but the $z$-statistic based on the median test is not significant. In fact, the $z$-statistic based on the quartile cutoff is strongly significant - suggesting a sizeable number of announcements exceeded their reference quartiles, but the reaction is not broad-based by the median test.
} 


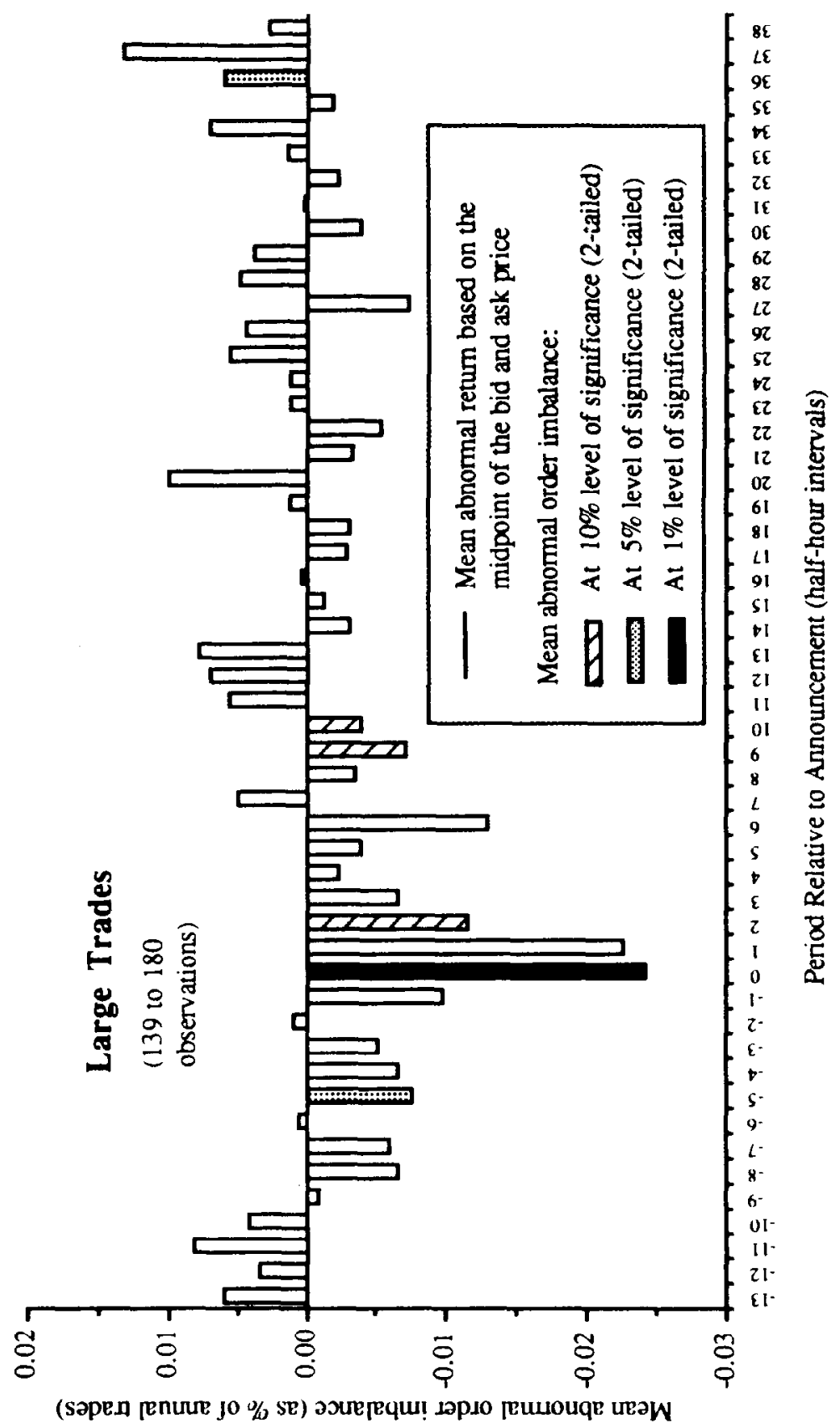




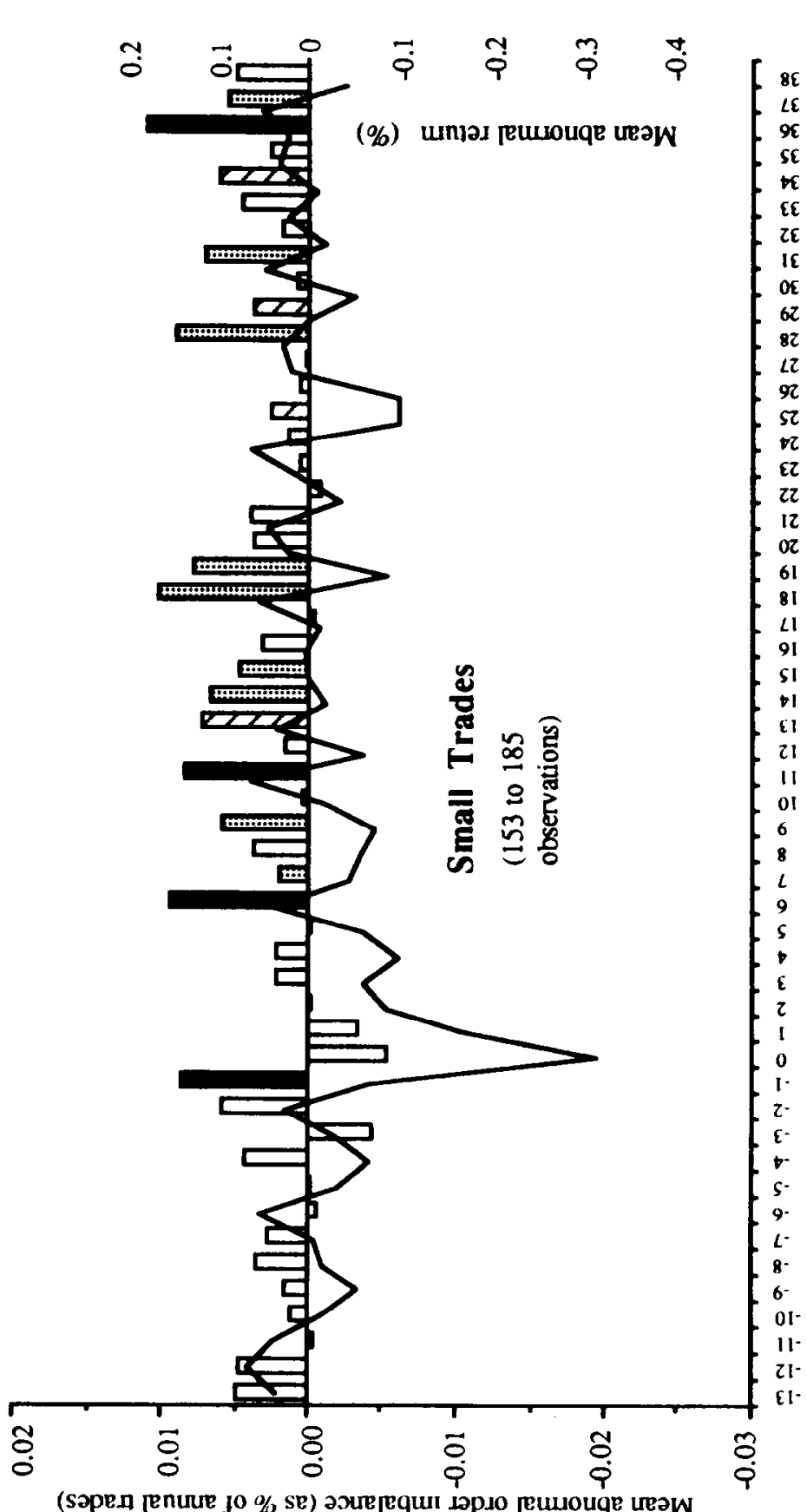

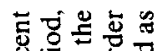

远诺

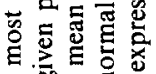

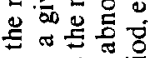

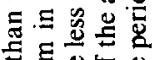

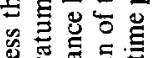

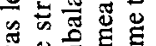

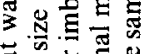

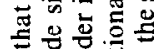

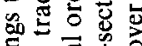

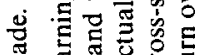

정

可要

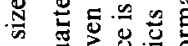

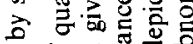

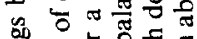

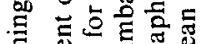

ह

的象范至

总实哥总

पु

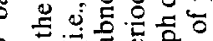

2 च

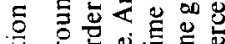

प

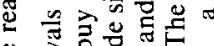

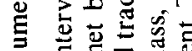

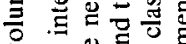

$>$ 号的

覀导的焉

记焉焉

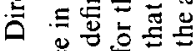

o

in

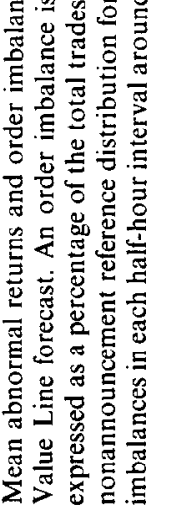




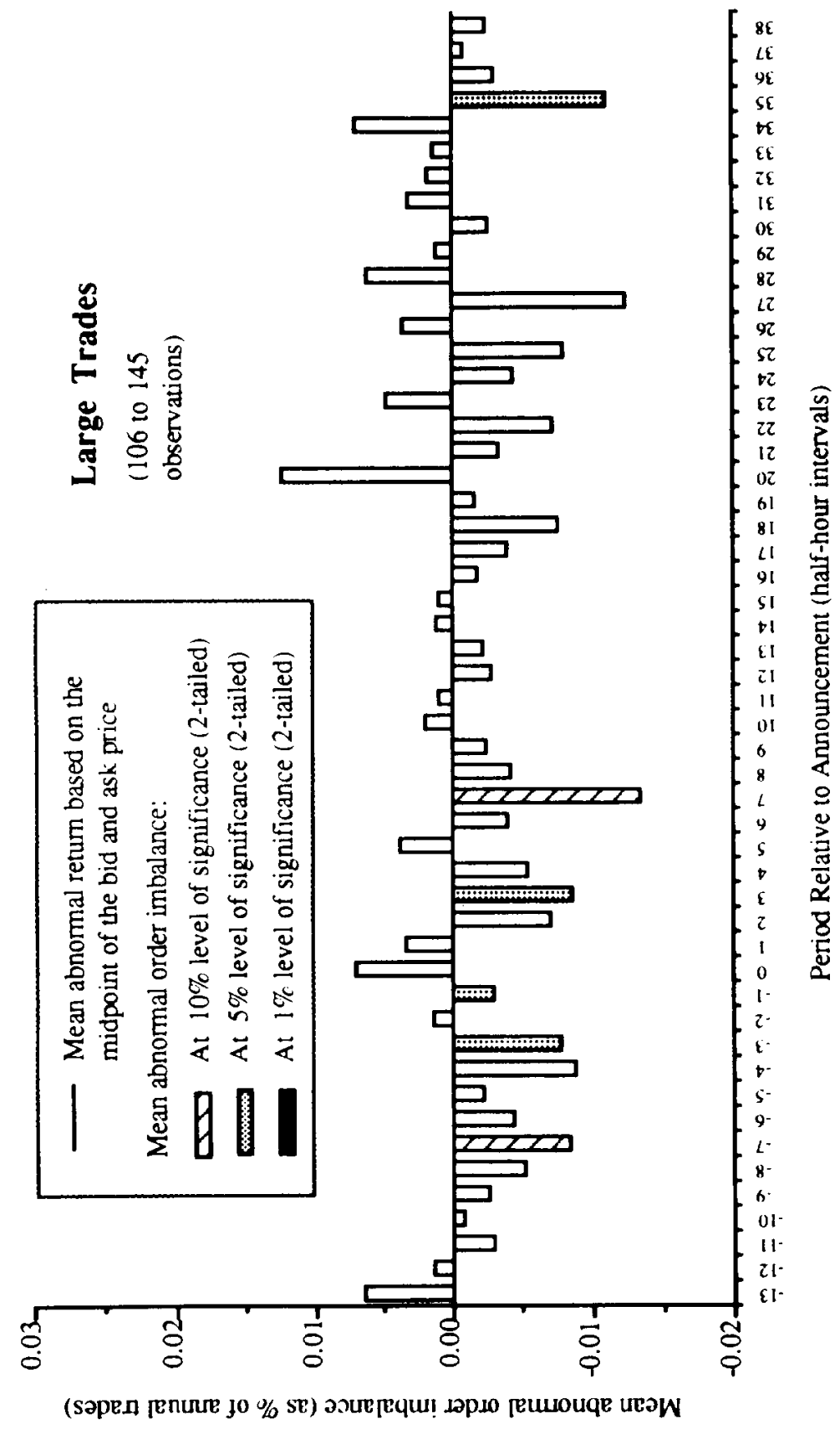




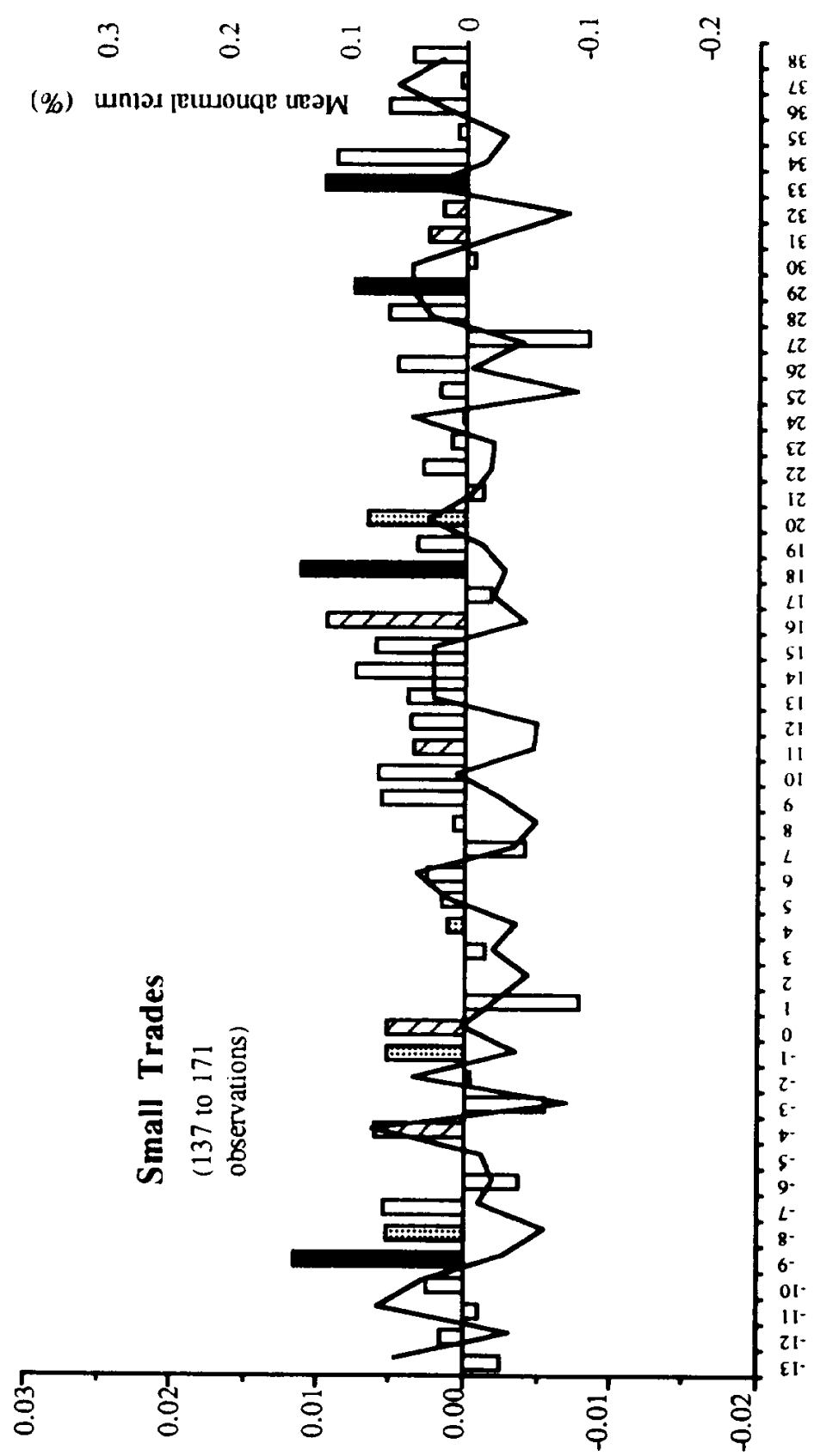

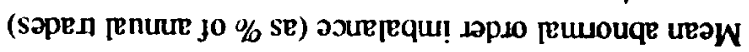

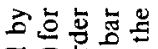

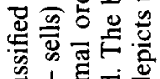

政

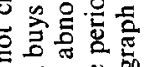

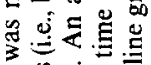

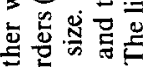

के

空空要要

要焉

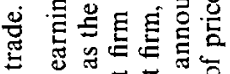

궁 可

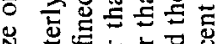

为

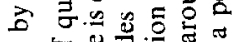

品

范

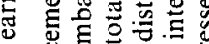

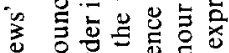

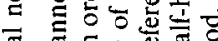

可

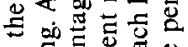

Ð

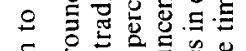

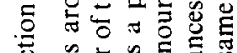

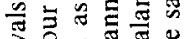

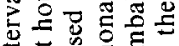

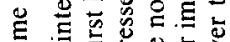

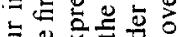

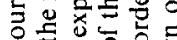

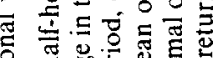

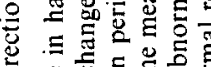

웡

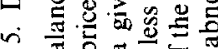

की

这.

可

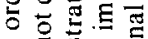

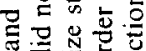

\%

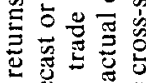

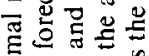

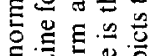

类步

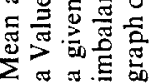




\subsection{Sensitivity of results to firm size and trading volume}

Since small firms tend to have a higher proportion of small trades, the question arises as to whether the earlier results are a small firm phenomenon. This question is also of concern in light of prior findings that earnings announcements of small firms are associated with stronger price and volume reactions [Freeman (1987), Atiase (1985), and Bamber (1987)]. The weaker reaction in small trades seems, at first blush, to be inconsistent with the stronger volume reaction expected in small firms (which have a greater proportion of small trades). Similarly, firms that trade infrequently experience a greater proportion of small trades, so that the small trade effect may be driven solely by firms with lower trading volume.

Tables 3 and 4 report summary results for subsamples formed on the basis of firm size (defined in terms of the total market capitalization at the beginning of the year) and trading volume (defined in terms of the average number of trades per day). Results for the full sample arc also reported in the first column for comparison. The small firms are, on average, less than one tenth the size of large firms. There is also a greater proportion of small trades in small firms $(63.9 \%)$ than in large firms $(38.7 \%)$.

Consistent with prior findings, table 3 shows that the volume reaction $(C M A V)$ is stronger for small firms than for large firms. This holds for both trade sizes, so both small and large traders respond more strongly in the small firms. The results are similar for the trading volume portfolios, as the $C M A V$ reaction is stronger in the low volume firms than in the high volume firms. Table 3 also shows that the reaction in small trades is 'weaker' than the reaction in large trades for all firms and for both 'good' and 'bad' news subsamples.

Table 4 reports the cumulative directional volume reaction ( $C M A D)$ over a four-day event interval. The $C M A D$ measure is the mean abnormal directional imbalance, summed over half-hour intervals -13 to +38 relative to the Broad Tape release time. The results show directional volume ( $C M A D)$ is not significantly positive for large trades in any of the portfolios, even for the 'good' and 'bad' news samples. Apparently the abrupt order imbalance in the half hour of the announcement is diluted over the four-day trading window, so the average $C M A D$ is no longer significant. However, the same measure is significantly positive for the small trades in all portfolios. The actual magnitude of the small trade $C M A D$ measure is lower in the large firms and the high volume firms, but this is consistent with the lower overall abnormal volume ( $C M A V)$ in these firms. It appears small traders do not respond as strongly in large and more frequently traded firms, but to the extent there is a small trade reaction, the trades are primarily buys. 
Table 3

Abnormal volume by trade size, firm size, and trading volume.

\begin{tabular}{|c|c|c|c|c|c|}
\hline & \multirow[b]{2}{*}{$\begin{array}{l}\text { Full } \\
\text { sample }\end{array}$} & \multicolumn{2}{|c|}{$\begin{array}{c}\text { Firm size } \\
\text { (market capitalization) }\end{array}$} & \multicolumn{2}{|c|}{$\begin{array}{l}\text { Trading volume } \\
\text { (trades per day) }\end{array}$} \\
\hline & & Small & Large & Low & High \\
\hline \multicolumn{6}{|l|}{ Firm statistics } \\
\hline $\begin{array}{l}\text { Number of firms } \\
\text { Average size at beginning of }\end{array}$ & 230 & 115 & 115 & 115 & 115 \\
\hline & 2,003 & 267 & 3,738 & 402 & 3,603 \\
\hline $\begin{array}{l}\text { (trades per day) } \\
\text { Proportion of small trades }\end{array}$ & $\begin{array}{r}70.0 \\
45.0 \%\end{array}$ & $\begin{array}{r}27.6 \\
63.9 \%\end{array}$ & $\begin{array}{r}113.9 \\
38.7 \%\end{array}$ & $\begin{array}{r}21.4 \\
42.0 \%\end{array}$ & $\begin{array}{r}120.1 \\
60.6 \%\end{array}$ \\
\hline $\begin{array}{l}\text { All earnings } \\
\text { announcements }\end{array}$ & 607 & 298 & 309 & 298 & 309 \\
\hline \multicolumn{6}{|l|}{$\begin{array}{l}\text { Abnormal volume } \\
(C M A V)^{\mathrm{a}}\end{array}$} \\
\hline All trades & $\begin{array}{l}0.224^{* *} \\
0.285^{* *}\end{array}$ & $\begin{array}{l}0.313^{* *} \\
0.286^{* *}\end{array}$ & $\begin{array}{l}0.137^{* *} \\
0.188^{* *}\end{array}$ & $\begin{array}{l}0.300^{* *} \\
0390^{* *}\end{array}$ & $\begin{array}{l}0.147^{* *} \\
0.180^{* *}\end{array}$ \\
\hline Small trades & $0.162^{* *}$ & $0.260^{* *}$ & $0.067^{* *}$ & $0.230^{* *}$ & $0.094^{* *}$ \\
\hline $\begin{array}{l}\text { Good news } \\
\text { announcements }\end{array}$ & 261 & 116 & 145 & 113 & 148 \\
\hline \multicolumn{6}{|l|}{$\begin{array}{l}\text { Abnormal volume } \\
(C M A V)^{\mathrm{a}}\end{array}$} \\
\hline All trades & $0.217^{* *}$ & $0.344^{* *}$ & $0.114^{* *}$ & $0.316^{* *}$ & $0.141^{* *}$ \\
\hline Large trades & $0.276^{* *}$ & $0.420^{* *}$ & $0.144^{* *}$ & $0.400^{* *}$ & $0.165^{* *}$ \\
\hline Small trades & $0.165^{* *}$ & $0.306^{* *}$ & $0.048^{* *}$ & $0.258^{* *}$ & $0.090^{* *}$ \\
\hline $\begin{array}{l}\text { Bad news } \\
\text { announcements }\end{array}$ & 240 & 116 & 124 & 116 & 124 \\
\hline \multicolumn{6}{|l|}{$\begin{array}{l}\text { Abnormal volume } \\
(C M A V)^{\mathrm{a}}\end{array}$} \\
\hline All trades & $0.246^{* *}$ & $0.335^{* *}$ & $0.163^{* m}$ & $0.349^{* *}$ & $0.150^{* *}$ \\
\hline $\begin{array}{l}\text { Large trades } \\
\text { Small trades }\end{array}$ & $0.331^{* *}$ & $0.414^{* *}$ & $0.231^{* *}$ & $0.463^{* *}$ & $0.189^{* *}$ \\
\hline Smail trades & $0.176^{* *}$ & $0.270^{* *}$ & $0.082^{* *}$ & $0.258^{* *}$ & $0.093^{* *}$ \\
\hline $\begin{array}{l}\text { "Cumulative mean abnorma } \\
\text { half-hour interval from - } 13 \\
\text { a percent of total annual trade } \\
\text { same time interval (four tradi } \\
\text { asterisks indicate significance } \\
\text { 'Announcements of earning } \\
\text { news', announcements of earn } \\
\text { 'bad news'. }\end{array}$ & $\begin{array}{l}\text { lume ( } C M \\
+38 \text { relati } \\
\text { that size c } \\
\text { days) is } 1.5 \\
\text { he } 5 \% \text { an } \\
\text { lat exceed } \\
\text { that are lo }\end{array}$ & $\begin{array}{l}V) \text { is the su } \\
\text { to the Broa } \\
\text { s. As refere } \\
\% \text { of total } \\
1 \% \text { levels in } \\
\text { e most rece } \\
\text { than the m }\end{array}$ & $\begin{array}{l}\text { f the mea } \\
\text { ape anno } \\
\text { the avera } \\
\text { ual trades } \\
\text { vo-tailed } t \\
\text { Value Lin } \\
\text { recent Val }\end{array}$ & $\begin{array}{l}\text { ormal vo } \\
\text { nent time } \\
\text { ormal' vo } \\
\text { le }\left(^{*}\right) \text { an } \\
\text { cast are } \\
\text { ne foreca }\end{array}$ & $\begin{array}{l}\text { e for each } \\
\text { oressed as } \\
\text { e over the } \\
\text { juble }\left({ }^{* *}\right) \\
\text { ned 'good } \\
\text { re deemed }\end{array}$ \\
\hline
\end{tabular}


Table 4

Abnormal directional volume by trade size, firm size, and trading volume.

\begin{tabular}{|c|c|c|c|c|c|}
\hline & \multirow{2}{*}{$\begin{array}{l}\text { Full } \\
\text { sample }\end{array}$} & \multicolumn{2}{|c|}{$\begin{array}{c}\text { Firm size } \\
\text { (market capitalization) }\end{array}$} & \multicolumn{2}{|c|}{$\begin{array}{l}\text { Trading volume } \\
\text { (trades per day) }\end{array}$} \\
\hline & & Small & Large & Low & High \\
\hline \multicolumn{6}{|l|}{ Firm statistics } \\
\hline $\begin{array}{l}\text { Number of firms } \\
\text { Average size at beginning of }\end{array}$ & 230 & 115 & 115 & 115 & 115 \\
\hline $\begin{array}{l}\text { year (\$million) } \\
\text { Average trading volume }\end{array}$ & 2,003 & 267 & 3,738 & 402 & 3,603 \\
\hline $\begin{array}{l}\text { (trades per day) } \\
\text { Proportion of small trades }\end{array}$ & $\begin{array}{r}70.0 \\
45.0 \%\end{array}$ & $\begin{array}{r}27.6 \\
63.9 \%\end{array}$ & $\begin{array}{r}113.9 \\
38.7 \%\end{array}$ & $\begin{array}{r}21.4 \\
42.0 \%\end{array}$ & $\begin{array}{r}120.1 \\
60.6 \%\end{array}$ \\
\hline $\begin{array}{l}\text { All earnings } \\
\text { announcements }\end{array}$ & 607 & 298 & 309 & 298 & 309 \\
\hline $\begin{array}{l}\text { Abnormal direction }(C M A D) \\
\text { All trades } \\
\text { Large trades } \\
\text { Small trades }\end{array}$ & $\begin{array}{c}0.063^{* *} \\
-0.030 \\
0.144^{* *}\end{array}$ & $\begin{array}{l}0.108^{* *} \\
-0.112 \\
0.217^{* *}\end{array}$ & $\begin{array}{l}0.030^{*} \\
0.002 \\
0.090^{* *}\end{array}$ & $\begin{array}{l}0.116^{* *} \\
-0.081 \\
0.246^{* *}\end{array}$ & $\begin{array}{c}0.098^{* *} \\
-0.013 \\
0.080^{* *}\end{array}$ \\
\hline $\begin{array}{l}\text { Good news } \\
\text { announcements }\end{array}$ & 261 & 116 & 145 & 113 & 148 \\
\hline $\begin{array}{l}\text { Abnormal direction (CMAD) } \\
\text { All trades } \\
\text { Large trades } \\
\text { Small trades }\end{array}$ & $\begin{array}{c}0.038 \\
-0.024 \\
0.106^{* *}\end{array}$ & $\begin{array}{c}0.061 \\
-0.112 \\
0.166^{* *}\end{array}$ & $\begin{array}{l}0.021 \\
0.000 \\
0.071^{* *}\end{array}$ & $\begin{array}{c}0.060 \\
-0.121 \\
0.199^{* *}\end{array}$ & $\begin{array}{c}0.024 \\
-0.002 \\
0.064^{* *}\end{array}$ \\
\hline $\begin{array}{l}\text { Bad news }{ }^{\mathrm{h}} \\
\text { announcements }\end{array}$ & 240 & 116 & 124 & 116 & 124 \\
\hline $\begin{array}{l}\text { Abnormal direction (CMAD) } \\
\text { All trades } \\
\text { Large trades } \\
\text { Small trades }\end{array}$ & $\begin{array}{c}0.067^{* *} \\
-0.058 \\
0.168^{* *}\end{array}$ & $\begin{array}{l}0.123^{* *} \\
-0.123 \\
0.268^{* *}\end{array}$ & $\begin{array}{c}0.028 \\
-0.009 \\
0.095^{* *}\end{array}$ & $\begin{array}{l}0.141^{* *} \\
-0.061 \\
0.304^{* *}\end{array}$ & $\begin{array}{c}0.020 \\
-0.040 \\
0.087^{* *}\end{array}$ \\
\hline
\end{tabular}

aCumulative mean abnormal direction $(C M A D)$ is the sum of the mean abnormal direction for each half-hour interval from -13 to +38 relative to the Broad Tape announcement time. The mean abnormal direction is the number of buys minus the number of sells, expressed as a percent of total annual trades in that size class. As reference, the average 'normal' volume over the same time interval (four trading days) is $1.58 \%$ of total annual trades. Single $\left({ }^{*}\right)$ and double $\left({ }^{* *}\right)$ asterisks indicate significance at the $5 \%$ and $1 \%$ levels in two-tailed tests.

${ }^{b}$ Announcements of earnings that exceed the most recent Value Line forecast are deemed 'good news', announcements of earnings that are less than the most recent Value Line forecast are deemed 'bad news'. 


\subsection{Results aligned by time-of-day}

The slower response of the small traders may be attributable to their use of a secondary information source, such as the Wall Street Journal, which is typically made available prior to the market open on day +1 relative to the Broad Tape announcement. Fig. 6 shows the mean abnormal volume for each half-hour interval of each day for days -1 to +2 for both large and small trades. There was little abnormal volume in either size class on day -1 . The abnormal volume on day 0 is fairly evenly distributed for large trades but seems stronger for small trades in the afternoon. Consistent with an overnight processing of information or a response to a secondary information source, volume in the first half hour of trading on day +1 is abnormally high for both trade strata. These findings no doubt understate the actual reaction, since the opening trade of the day has been eliminated. Again, the abnormal volume persists through day +2 in both size strata.

Fig. 7 presents the mean abnormal directional imbalance measures by timeof-day for all intraday earnings releases. The large trade directional response is mixed for all four days, but the small trade buying activities appear to be concentrated on days $-1,+1$, and +2 . The strongest buying imbalance appears in the small trades during the morning of day +1 . Although not reported, dividing the sample by good, bad, and neutral news produces very similar results. In each case, significant abnormal buying in small trades is observed for days +1 and +2 . On day -1 , the evidence is mixed for good news releases, but abnormal buying in small trades is observed for bad and neutral news.

\section{Summary}

Capital-market-based accounting research has been characterized by two themes: the sophistication of the market to accounting numbers and the informativeness of accounting news releases. On the one hand, stock prices anticipate earnings news [Ball and Brown (1968), Patell and Wolfson (1981)], respond quickly to earnings releases [Patell and Wolfson (1984)], and are not misled by accounting changes [Ball (1972), Biddle and Lindahl (1982)]. On the other hand, price and volume reactions associated with accounting releases are widely interpreted as evidence of their usefulness to investors [Beaver (1968), Morse (1981), Bamber (1986, 1987)]. Yet these findings have been based on aggregate measures that implicitly assume market participants are a homogeneous group. Little is known about the sophistication of small traders and the usefulness of earnings releases to these traders.

This paper presents evidence on the differential intraday volume reactions in the large and small trade strata around earnings announcements. The evidence shows the small trade reaction is both weaker (as a proportion of annual trades 


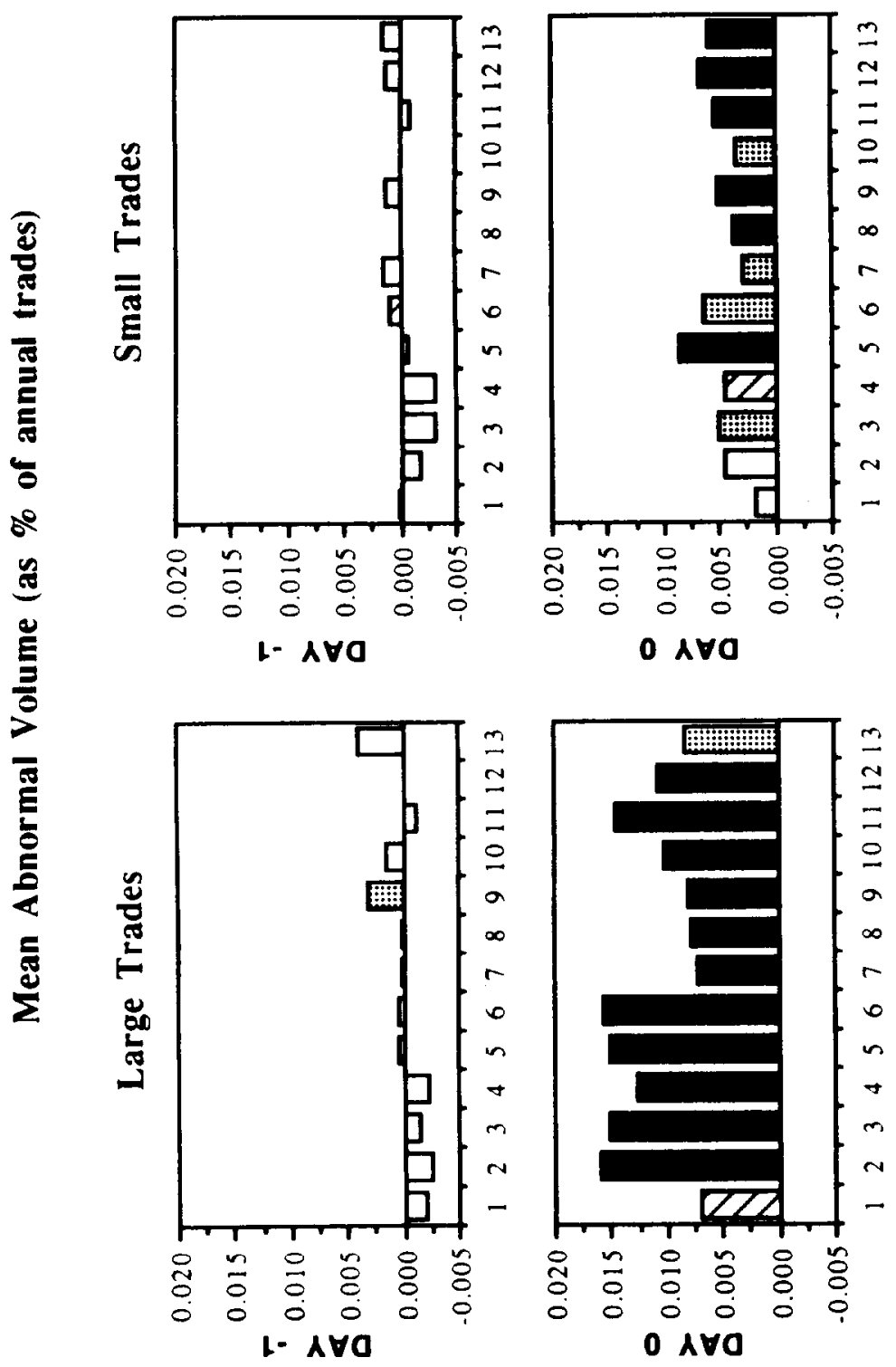




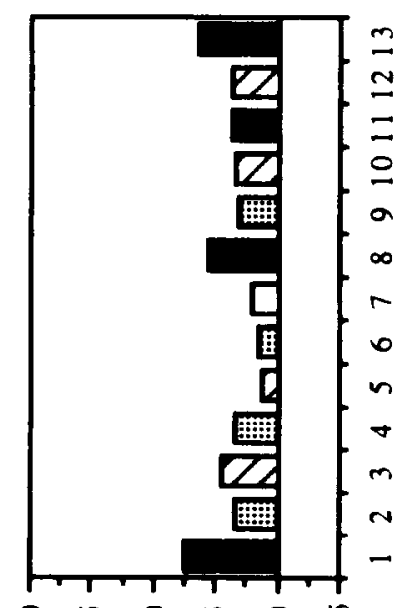

รั

$1+1 \forall 0$

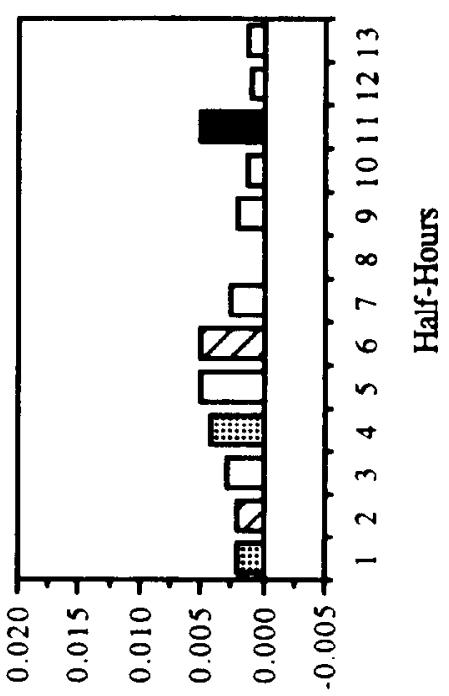

$\boldsymbol{Z}^{+} \mathbf{A} \mathbf{0}$

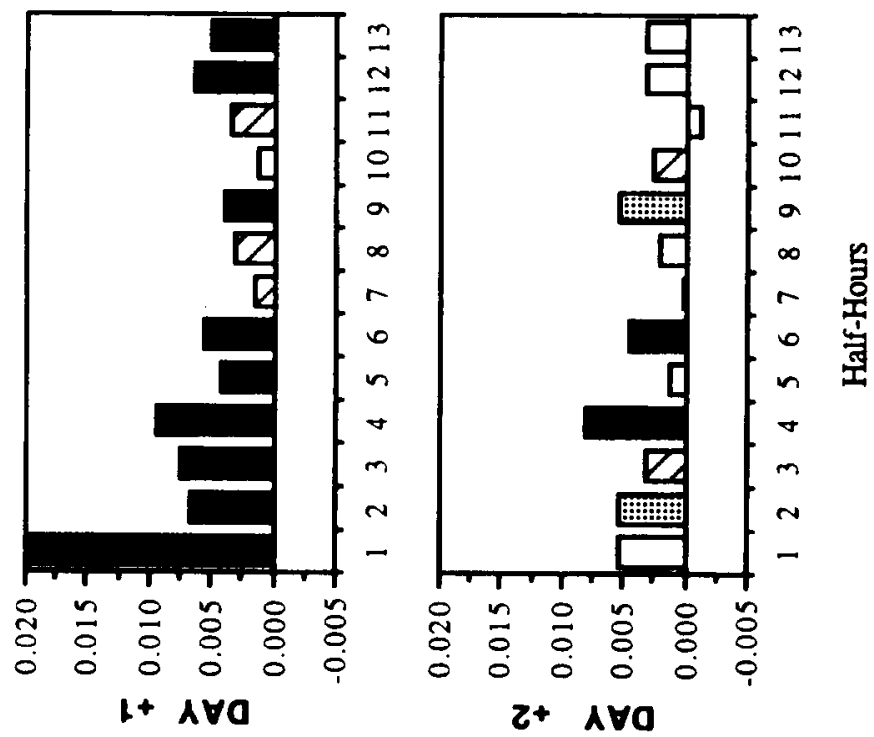

官苛苛

递

तै 过

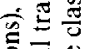

웜

窟

5

5 品

可

6.

灵 范

$\frac{\circ}{0}$

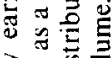

츤물

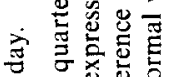
ठ ठ \&̊ है

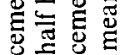
视品

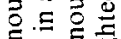
蛋

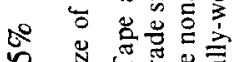
疋可焉 응

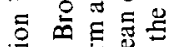
焉里 过吉导

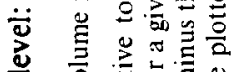
잉

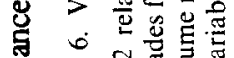
热 i 은

Т苗总 的寻 苛 है

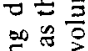
E

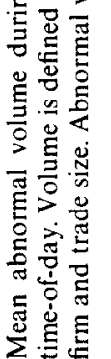




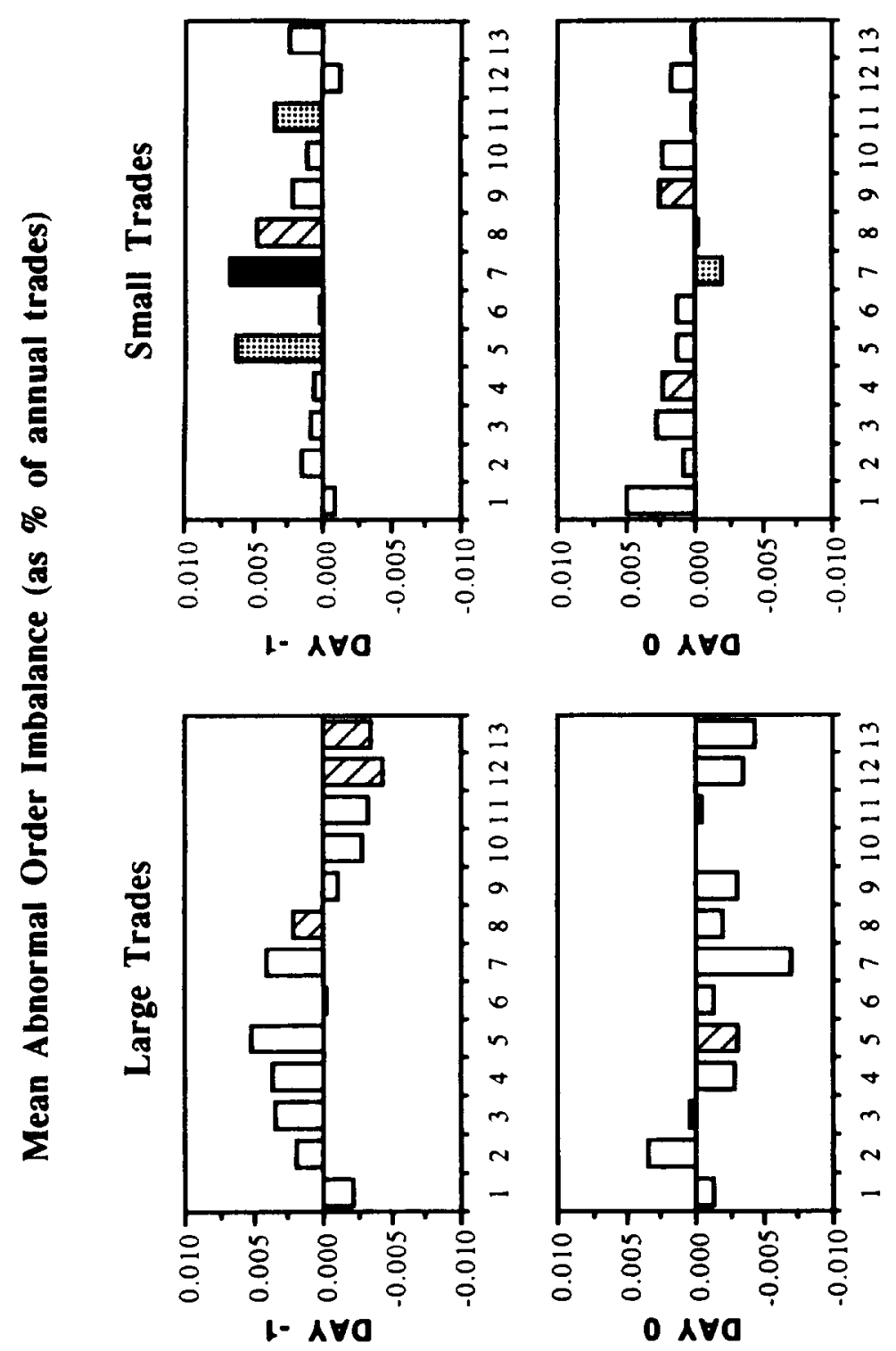




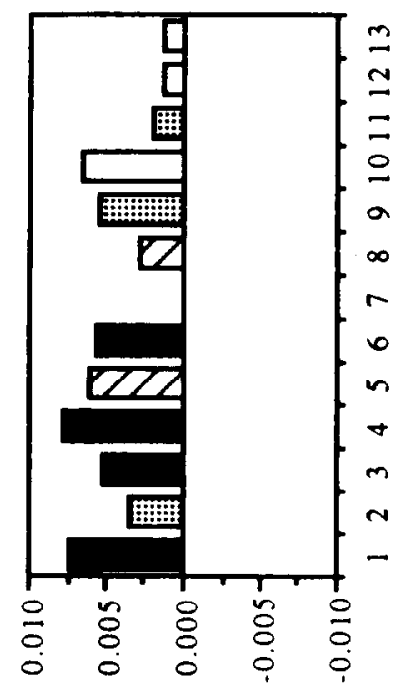

เ $+\lambda \forall 0$

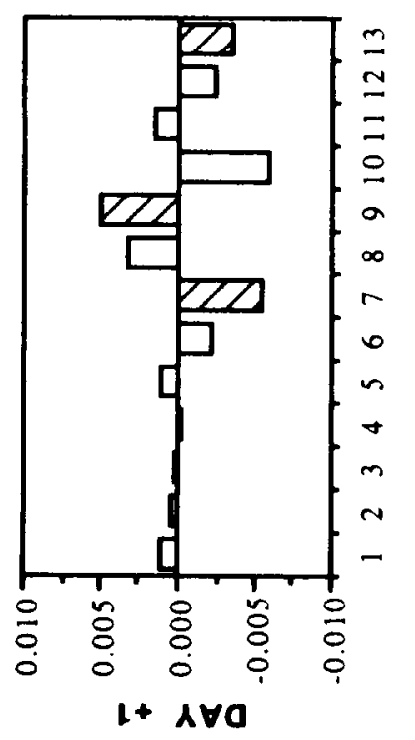

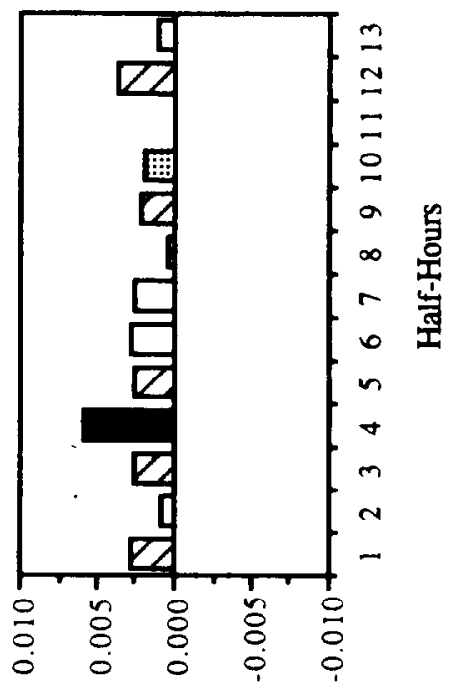

$\boldsymbol{Z}+\Lambda \forall 0$

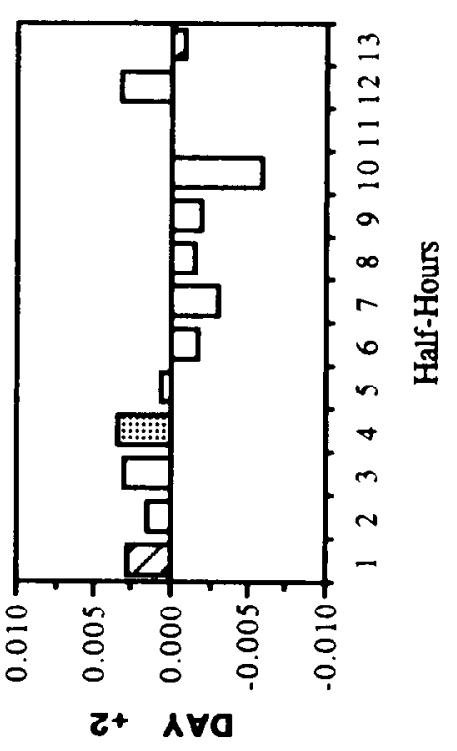

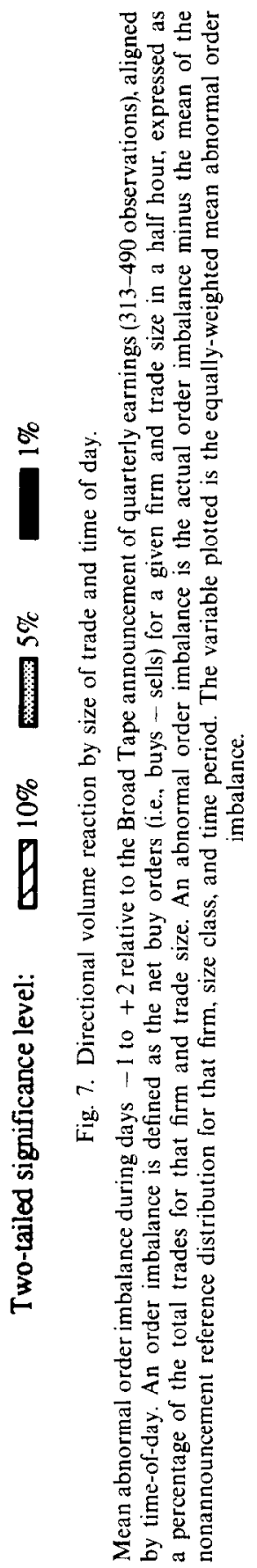


in each trade size) and slower (in terms of the manifestation of abnormal volume relative to the Broad Tape release time). In addition, while 'good' ('bad') news triggers a brief but intense buying (selling) imbalance in the large trades, small trades are characterized by a persistent period of unusually high buying activity for both good and bad news releases. Collectively, the evidence suggests heterogeneous behavior in the instigators of small and large trades. If trade size is a credible proxy for individual and institutional activities, the evidence suggests these two groups differ in their reaction to the same earnings news.

The surprising propensity of small traders to be net buyers during the earnings announcement period does not seem to be readily explained by existing theories. For example, in Admati and Pfleiderer (1988) some traders trade for liquidity reasons but have discretion over the timing of their trades. In that model, an intraday clustering of trades arises endogenously because discretionary liquidity traders find it advantagcous to time their trades to coincide with the activities of informed traders. If we assume small traders are generally less informed, they may attempt to reduce their informational disadvantage by delaying trade execution until after earnings announcements. This results in increased liquidity-based (noninformational) trading in the post-announcement period. However, there is no directional prediction in this theory. In particular, there is no reason to expect this increased volume to be predominantly buys. Nor does the theory explain the small traders' propensity to buy the day before the announcement, when there is little excess volume.

One concern is that these findings are due to the breaking up of large trades during fast trading after an earnings announcement. While incoming trades are not generally split in the processing, it is certainly possible that some small trades after an earnings release derive from the splitting of larger trades. However, the buy/sell classification algorithm is such that small trades created by the breaking up of large trades are directionally the same as the large trades. This is not what we observe, since small trades are predominantly buys while large trades display no such pattern.

It has also been suggested that the small trade behavior may be attributable to systematic differences in risk preferences. Since risk is known to increase during earnings announcement periods, small traders who are extremely risk-averse might sell before the announcements and buy afterwards to avoid the risk of holding the security over the announcement period. The pre-announcement selling is more dispersed and therefore is not detectable while the post-announcement buying is more concentrated and is observed. Although this strategy involves trading costs, it has been argued that for discretionary liquidity traders in the Admati and Pfleiderer sense, these costs are not germane to the decision to trade. For these traders, it may be advantageous to delay purchases of a security until after the announcement, when the risk of ownership is lower. 
This explanation has several potential problems. First, there is no evidence that risk preferences are systematically different between large and small traders. The extant evidence shows a high concentration of small individual traders in such high-beta securities as small firms, over-the-counter stocks, and initial public offerings, as well as low-beta securities such as utilities [Lee, Shleifer, and Thaler (1991)]. So, if risk is defined in a Capital Asset Pricing Model (CAPM) context, small traders do not seem systematically more risk-averse. If large and small traders are both risk-averse, the obvious question is why there isn't a similar propensity to buy in the large trade stratum. Second, contrary to the theory, the abnormal buying by small traders begins before the Broad Tape announcement date. Third, while the phenomenon is pervasive in the data, there is no anecdotal evidence of this practice among individual investors.

Another explanation is that the buys and sells of small traders are the results of different decision processes. Specifically, small investor buy decisions are associated with news events which bring the security to small investors' attention, while sell decisions are driven more by consumption or liquidity needs. Events such as a Wall Street Journal article spur interest and elicit higher buys regardless of the nature of the news. In other words, it isn't the news content of the event per se, but the attention given to the firm, that triggers the small trade response we observe. One variation of this explanation includes the asymmetric cost of short-selling. Specifically, media coverage may spur both large and small traders to action, but small trader sells are curtailed by the higher proportional costs of short-selling in small amounts. This explanation implies that the propensity toward buys is not specific to earnings news and will appear in small trades for any announcement that receives sufficient media coverage. Given our current understanding of small investor behavior, it is difficult to determine whether these buy/sell patterns are economically rational or in some sense suboptimal.

One explanation that raises serious questions about the small traders' discernment is based on the obscrvation that small traders rely heavily on advisors in their investment decisions [SRI (1987)]. It is known that financial analysts and brokers make far more buy recommendations than sell recommendations [Groth, Lewellen, Schlarbaum, and Lease (1979) report that, based on a sample of 6,000 recommendations, six buy recommendations are issued for every one sell recommendation]. If brokerage houses and other advisory services routinely contact their clients around the time of earnings announcements, it is possible that the reaction observed is a response to the advice from their advisors. Since the advice is heavily one-sided, an abnormal buying imbalance results.

Clearly, many questions remain. If indeed there exists a distinct individual segment in the investing community, with its own information needs and trading patterns, the implications for accounting and finance research could be 
far-reaching. It is my hope and expectation that this study will stimulate further thought in this direction.

\section{Appendix: Inferring trade direction}

The direction of individual trades is inferred by the following algorithm from Lee and Ready (1991). Only NYSE-issued quotes which are BBO-eligible were used (a quote is BBO-eligible if it qualifies for the National Association of Security Dealers' Best-Bid-Or-Offer calculation):

(1) Current Quote Match - If the trade price is at the bid or ask and the current quote was not revised within the last five seconds, then the direction of the trade is determined by the current quote (i.e., a buy if it's at the ask and a sell if it's at the bid).

(2) Delayed Quote Match - If the current quote is less than five seconds old, it is ignored and the trade price is compared to the bid and ask prices of the previous quote.

(3) Outside the Spread - If the trade price, when compared to the quote in either step 1 or 2 , is greater than the ask (less than the bid), then the transaction is deemed a buy (sell).

(4) Tick Test - If the trade is at the midpoint of the spread or if a BBO-eligible quote is not available, the tick test is used to determine trade direction. In other words, if the last price change was positive (negative), then this trade is

Table A.1

Number of trades ordered by classification.

\begin{tabular}{|c|c|c|c|c|c|c|}
\hline \multirow[b]{2}{*}{ Classified by: } & \multicolumn{2}{|c|}{ All trades } & \multicolumn{2}{|c|}{ Large trades } & \multicolumn{2}{|c|}{ Small trades } \\
\hline & Buys & Sclls & Buys & Sells & Buys & Sells \\
\hline Current quote match & $1,157,796$ & $1,274,563$ & 627,600 & 616,819 & 530,196 & 657,744 \\
\hline Delayed quote match & 155,584 & 150,503 & 128,571 & 118,901 & 27,013 & 31,602 \\
\hline Outside spread & 11,025 & 13,363 & 6,682 & 7,326 & 4,343 & 6,037 \\
\hline Tick test & 466,336 & 431,559 & 265,484 & 232,634 & 200,852 & 198,925 \\
\hline Proximity to bid/ask & 185,880 & 182,267 & 112,898 & 103,134 & 72,982 & 79,133 \\
\hline Total & $\underline{1,976,621}$ & $2,052,255$ & $1,141,235$ & $1,078,814$ & $\underline{835,386}$ & 973,441 \\
\hline $\begin{array}{l}\text { As } \% \text { of total trades } \\
\text { in each size stratum }\end{array}$ & $49.06 \%$ & $50.94 \%$ & $51.41 \%$ & $48.59 \%$ & $46.18 \%$ & $53.82 \%$ \\
\hline
\end{tabular}

${ }^{\mathrm{a}} \mathrm{A}$ total of 47,314 trades (or $1.2 \%$ of all trades) were not determinable in direction and were excluded from the summary above. Note that unless offsetting behavior occurs in the submission of limit orders, these statistics indicate small traders were net sellers during 1988 while large traders were net buyers. This is at least consistent with the market wisdom that small investors were largely bearish on the market after the 1987 crash - despite the strong overall market during 1988. 
deemed a buy (sell). All out-of-sequence trades are ignored in updating price changes.

(5) Proximity to Bid/Ask - If a trade is between the spread but not at the midpoint, then the trade is classified according to its proximity to the bid or ask price. Trades at prices above the midpoint are classified as sells and trades at prices below the midpoint are classified as buys.

(6) Indeterminable - This classification is assigned to a trade when none of the above conditions apply. Specifically, it applies to the first trade of the year for each firm and any trade which is reported out-of-sequence.

When the procedures above were applied to the trades in the sample firms, the number of trades classified by each step is as shown in table A.1.

\section{References}

Admati, Anat R. and Paul Pfleiderer, 1988, A theory of intraday patterns: Volume and price variability, Review of Financial Studies 1, 3-40.

Atiasc, R.K., 1985, Predisclosure information, firm capitalization, and security price behavior around earnings announcements, Journal of Accounting Research 23, 21-36.

Ball, Ray, 1972, Changes in accounting techniques and stock prices, Journal of Accounting Research 10, Suppl., 1-38.

Ball, Ray and P. Brown, 1968, An empirical evaluation of accounting income numbers, Journal of Accounting Research 6, 159-178.

Bamber, L.S., 1986, The information content of annual earnings releases: A trading volume approach, Journal of Accounting Research 24, 40-56.

Bamber, L.S., 1987, Unexpected earnings, firm size, and trading volume around quarterly earnings announcements, Accounting Review 25, 510-532.

Beaver, W.H., 1968, The information content of annual earnings announcements, Journal of Accounting Research 6, Suppl., 67-92.

Biddle, G.C. and F.W. Lindahl, 1982, Stock price reactions to LIFO adoptions: The association between excess returns and LIFO tax savings, Journal of Accounting Research 20, 551-588.

Chen, Louis K.C. and Josef Lakonishok, 1991, Institutional trades and intra-day stock price behavior, Working paper (University of Illinois, Urbana-Champaign, IL).

Copeland, Thomas E. and Daniel Galai, 1983, Information effects on the bid/ask spread, Journal of Finance 38, 1457-1469.

Cready, William M., 1988, Information value and investor wealth: The case of earnings announcements, Journal of Accounting Research 26, 1-27.

Cready, William M. and Patricia G. Mynatt, 1991, The information content of annual reports: A price and trading response analysis, Accounting Review 66, 291-312.

Financial Accounting Standards Board, 1978, Statement of financial accounting concepts no. 1 (FASB, Stamford, CT).

Freeman, R.N., 1987, The association between accounting earnings and security returns for large and small firms, Journal of Accounting and Economics 10, 195-228.

Groth, J.C.. W. Lewellen, G. Schlarbaum, and R. Lease, 1979, An analysis of brokerage house security recommendations, Financial Analysts Journal, 32-40.

Grundy, Bruce D. and Maureen McNichols, 1989, Trade and revelation of information through prices and direct disclosure, Keview of Financial Studies 2, 485-526.

Holthausen, Robert and Ro E. Verrecchia, 1990, The effect of informativeness and consensus on price and volume behavior, Accounting Review 65, 191-208.

Karpoff. Jonathan M., 1986, A theory of trading volume, Journal of Finance XLL, 1069-1087.

Kim, Oliver and Ro E. Verrecchia, 1991, Trading volume and price reactions of public announcements, Journal of Accounting Research 29, forthcoming. 
King, Ronald, Grace Pownall, and Gregory Waymire, 1991, Corporate disclosure and price discovery associated with NYSE temporary trading halts, Contemporaly Accounting Research, forthcoming.

Lakonishok, Josef and Edwin Maberly, 1990, The weekend effect: Trading patterns of individual and institutional investors, Journal of Finance 45, 231-243.

Lease, Ronald, Wilbur Lewellen, and Gary Schlarbaum, 1974, The individual investor: Attributes and attitudes, Journal of Finance 29, 313-333.

Lee, Charles M.C. and Mark Ready, 1991, Inferring trade directions from intraday data, Journal of Finance 46, 733-746.

Lee, Charles M.C., Andrei Shleifer, and Richard Thaler, 1991, Investor sentiment and the closed-end fund puzzle, Journal of Finance 46, 75-109.

Lewellen, Wilbur, Ronald Lease, and Gary Schlarbaum, 1977, Patterns of investment strategy and behavior among individual investors, Journal of Business 50, 296-333.

Morse, Dale, 1981, Price and trading volume reaction surrounding earnings announcements: A closer examination. Journal of Accounting Research, 374-383.

New York Stock Exchange, Public transaction study: Fourth quarter 1980, A research report.

New York Stock Exchange, Shareownership 1985, A survey.

Patell, James M. and Mark A. Wolfson, 1981, The ex ante and ex post price effects of quarterly earnings announcements reflected in option and stock prices, Journal of Accounting Research 19,434458 .

Patell, James M. and Mark A. Wolfson, 1982, Good news, bad news, and the intraday timing of corporate disclosures, Accounting Review 57, 509-527.

Patell, James M. and Mark A. Wolfson, 1984, The intraday speed of adjustment stock prices to earnings and dividend announcements, Journal of Financial Economics 13, 223-252.

Ritter, Jay R., 1988, The buying and selling behavior of individual investors at the turn of the year, Journal of Finance 43, 701-717.

Securities Industry Association, 1989. Trends: An analysis of emerging trends in the securities industry, vol. XV, no. II, March 16.

Shiller, Robert J. and John Pound, 1989, Survey evidence on diffusion of interest and information among investors, Journal of Behavior and Organization 12, 47-66.

Stanford Research Institute International, 1987, Investor information needs and the annual report (Financial Executives Research Foundation, Stanford, CA).

Yunker, James A. and Timothy L. Krehbiel, 1988, Investment analysis by the individual investor, Quarterly Review of Economics and Business, 90-101. 